Accepted Manuscript

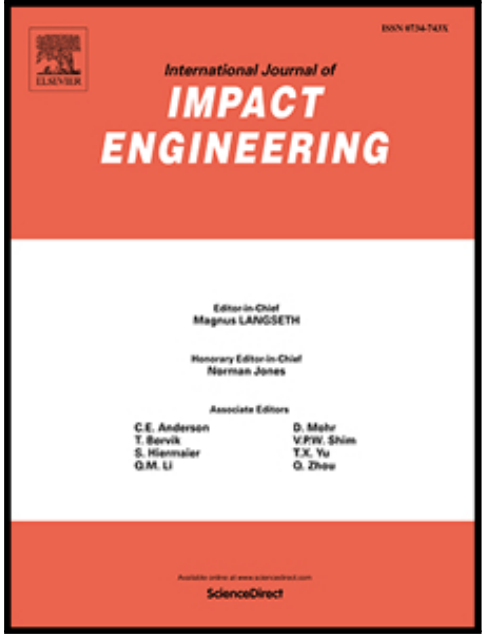

To appear in: $\quad$ International Journal of Impact Engineering

S0734-743X(16)30286-X

PII: 10.1016/j.jimpeng.2016.12.016

DOI: IE 2801

Reference:

21 May 2016

Received date:

Revised date: $\quad 27$ September 2016

Please cite this article as: Thong M. Pham, Hong Hao, Plastic Hinges and Inertia Forces in RC Beams under Impact Loads, International Journal of Impact Engineering (2016), doi: 10.1016/j.ijimpeng.2016.12.016

This is a PDF file of an unedited manuscript that has been accepted for publication. As a service to our customers we are providing this early version of the manuscript. The manuscript will undergo copyediting, typesetting, and review of the resulting proof before it is published in its final form. Please note that during the production process errors may be discovered which could affect the content, and all legal disclaimers that apply to the journal pertain. 


\section{Highlights}

- Formation and location of the plastic hinge in an RC beam.

- Verification of the distribution of inertia force.

- Shear force and bending moment of an RC beam subjected to impact loads.

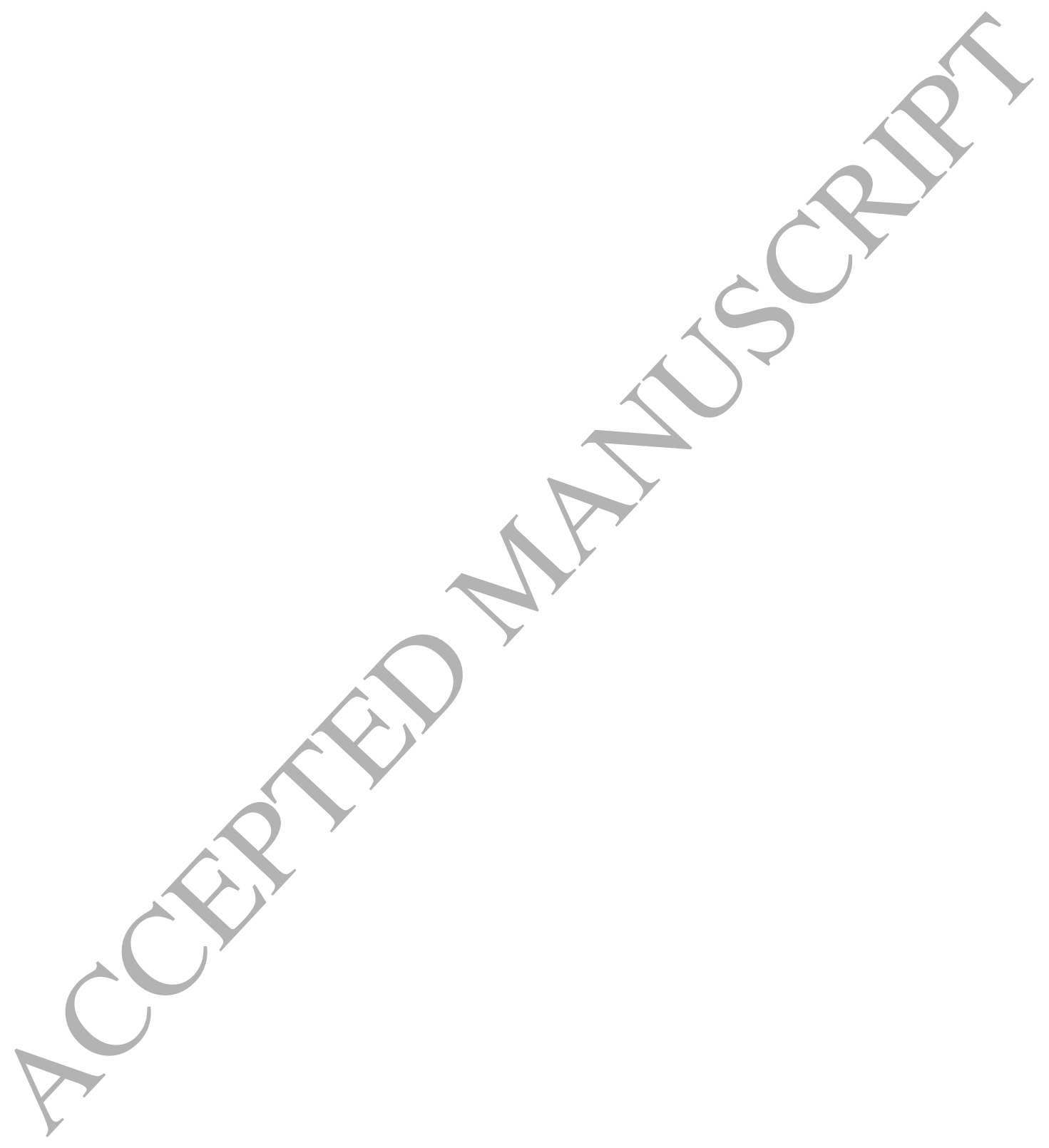




\title{
Plastic Hinges and Inertia Forces in RC Beams under Impact Loads
}

\author{
Thong M. Pham ${ }^{1}$ and Hong Hao ${ }^{2}$
}

\begin{abstract}
This study investigates the impact behavior of reinforced concrete beams and proposes a procedure to derive the shear force and bending moment diagrams. The assumption of linear distribution of the inertia force under impact load is examined against experimental and numerical results. The finding in this study has confirmed the linear inertia force distribution assumption along the beam up to the instant the impact force reaches its peak value. The position of plastic hinges is observed to have significant effects on the impact behavior of the beam. Under impact the plastic hinge does not necessarily reach the supports, and then only part of the beam within the stationary points is accelerated while the rest of the beam remains stationary. A procedure is proposed to predict the position of the stationary points, which is proven yielding reasonable results in comparison with experimental and numerical results. A flow chart is also provided to generate the shear force and bending moment diagrams for reinforced concrete beams under impact loads, which can be used in the design of concrete beams subjected to impact loads.
\end{abstract}

Keywords: Reinforced concrete; Impact force; Plastic hinge; Dynamic response; Inertia force.

\footnotetext{
${ }^{1}$ Research Fellow, Center for Infrastructural Monitoring and Protection, School of Civil and Mechanical Engineering, Curtin University, Kent Street, Bentley, WA 6102, Australia. Email: thong.pham@curtin.edu.au ${ }^{2}$ John Curtin Distinguished Professor, Center for Infrastructural Monitoring and Protection, School of Civil and Mechanical Engineering, Curtin University, Kent Street, Bentley, WA 6102, Australia (Corresponding author). Email: hong.hao@curtin.edu.au
} 


\section{Introduction}

Some reinforced concrete (RC) beams during their service life might be subjected to impulsive loads. The loading rate of impact load could be significantly higher compared to that of the quasi-static loads. The high loading rate may change the structural behavior and the failure modes. It has been observed in previous studies [1-3] that RC beams which are flexural-critical under static loads damaged by shear failure under impact loads. By analyzing the structural behavior and force equilibrium of impacted beams, Pham and Hao [3] have concluded that the shear force in a simply supported beam under impact increases faster than the resulting moment. This observation is supported by the results of the study by Saatci and Vecchio [1]. In such cases, the RC beams under impact could reach its shear strength before the flexural strength, leading to the shear failure. As commonly agreed, the impact force is primarily resisted by the inertial forces at very early moment of an impact event, which induces large shear forces in the beam $[1,4-6]$. Therefore, it is important to determine the inertia force distribution along the beam under impact loads. If the inertia force distribution and the impact force are known, shear force and bending moment along the beam can be straightforwardly derived. Hence the performance of the beam under impact loads can be predicted. Unfortunately, although impact energy is easily determined, it is not straightforward to reliably predict the impact loads on a structure from various sources such as drop weights. Moreover, how the inertia force along a RC beam under impact load would distribute is not well understood yet.

The impact behavior of RC beams is very different from those under quasi-static loads, such as the existence of the negative moment, local damage, and negative reaction. The main reason for these differences is caused by the inertia force and its distribution along the beam. More number of studies of inertia force distribution along steel beams under impact loads has 
been reported [7]. There has been a consensus that the inertia force distribution is linear along the beam under impact. Less number of studies of inertia force distribution of concrete beams under impact loads is available in literature. Banthia et al. [8] experimentally investigated the distribution of the inertial forces along concrete beams and concluded that the distribution is linear in the case of a plain concrete beam and sinusoidal in the case of an RC beam. The conclusions were derived based on the tests on small size beams with the clear span of 0.96 $\mathrm{m}$. In these beams, the authors attached three accelerometers to monitor the acceleration at three particular points. Recently, Saatci and Vecchio [1] monitored the acceleration along large $4.88 \mathrm{~m} \mathrm{RC}$ beams. On each beam, the authors placed five accelerometers to measure the acceleration at five different points. These testing results will be adopted in this study to examine the distribution of inertia forces.

Previous studies in the literature about impact behavior of $\mathrm{RC}$ beams often assume the inertia force distributes over the whole beams $[1,4-6,8,9]$. Although this assumption has been widely adopted in analyzing the impact behavior of RC beams, it has not been verified yet. This study thus examines the inertia force distribution as well as the location and the formation of plastic hinges.

As can be seen investigating the impact behavior of RC beams and then the distribution of inertia forces is essential for estimating the dynamic shear force and bending moment distributions in the beam. This study first briefly presents the impact behavior of RC beams under impact so that the crucial effect of the inertia force distribution on the resulting moment and shear force is discussed. The distribution of inertia forces is studied by both experimental results and numerical simulations. Finally a procedure for generating the shear force and bending moment diagrams under impact loads is presented for the design purpose.

\section{Impact Behavior of RC beams}


The equilibrium of an impacted beam is maintained by the participation of all the force components including the impact force, reaction force, and inertial force at any time during an impact event. When a moving object impacts a beam and accelerates it, the acceleration of the beam results in inertial resistances to the impact force in which their magnitudes can be estimated by multiplying the mass and acceleration along the beam. The balance condition of an impacted beam has been experimentally and numerically verified [1, 5]. Meanwhile, experimental results have shown that the maximum impact force was almost entirely resisted by the inertial forces, and the corresponding reaction force was very small or negligible as compared to the impact force $[1,2,5,10]$. Since the maximum impact forces in these tests were significantly higher than the corresponding reaction forces, these beams had a significant inertial resistance against impact loads.

In general, the impact behavior of RC beams can be examined by using spring-mass models and numerical simulations. The spring-mass models are divided into two common types consisting of either a single degree of freedom (SDOF) or a two DOF model. A few springmass models have been proposed to predict the dynamic behavior of beams [11-14]. However, these analytical models are initially proposed for steel beams and have not been verified for RC beams yet. In addition, SDOF models derived according to the design guides that take the entire beam into consideration and assume flexural response mode have some drawbacks as mentioned in the study by Hao [15], for example, it may accurately predict the dynamic response of structures only when the global deformation governs the response of the structure. If the structure is locally damaged or global response does not govern the behavior, SDOF may not yield good prediction. Previous studies have observed that local damage of structures rather than global damage are likely to occur under drop-weight tests $[5,11,16$, 17]. It is noted that the impact velocity from these drop-weight tests usually ranges from 1.7 
to $9.3 \mathrm{~m} / \mathrm{s}$ [9]. Therefore, structural response of $\mathrm{RC}$ beams under drop-weight tests or those having similar impact velocities may not be predicted well by using SDOF models.

\section{Impact force}

In the contemporary literature, models for prediction of the impact forces are usually applied for concrete panels or composite plates [13, 18-25]. There have been three common approaches to predict impact loads on structures, including the contact law, energy-based approach, and spring-mass models which are divided into two types consisting of either an SDOF or a two DOF. A review of existing models was presented in the study by Pham and Hao [9]. The two DOF spring-mass model has one spring representing the linear stiffness of the structure $\left(k_{2}\right)$, another spring representing the local indentation $\left(k_{1}\right)$, the mass of the projectile $\left(G_{1}\right)$ and the effective mass of the structure $\left(G_{2}\right)$ as shown in Fig. 1. The stiffness of the structure can be determined to account for both the shear and bending deformation. From the free body diagram of the system, the equations of motion can be written as [13]:

$$
\begin{gathered}
G_{1} \ddot{x}_{1}+k_{1}\left(x_{1}-x_{2}\right)=0 \\
G_{2} x_{2}+k_{2} x_{2}+k_{1}\left(x_{2}-x_{1}\right)=0
\end{gathered}
$$

where $x_{1}$ and $x_{2}$ are respectively movements of the projectile and the beam. A solution to solve the above equations can be found in the study by Abrate [13]. There are two scenarios for the SDOF spring-mass model. In the first instance, the overall deflection of the structure is neglected as compared to the local indentation. In such cases, the spring in Fig. 1 represents the contact stiffness and the equation of motion can be written as:

$$
G \ddot{x}+k_{1} x^{\frac{3}{2}}=0
$$

The second scenario neglects the local indentation but includes only the deflection of the structure. The equation of motion of the corresponding SDOF model is: 


$$
G \ddot{x}+k_{b} x+k_{m} x^{3}=0
$$

where $k_{b}$ is the stiffness of the structure representing the bending flexural and $k_{m}$ is the stiffness of the structure accounting for the membrane effect. This model requires iterative solutions which are not straightforward and no such models have been calibrated for RC beams yet. Moreover, determination of the various parameters in a real impact case is also not straightforward. For example, the stiffness of the beam deformation and indentation are not necessarily constants under large impact loads. They not only depend on the structural dimensions and material properties, but also are strongly affected by the interaction between impactor and beam, and amplitude of impact loads and structural deformation.

The impact force $(P)$ can be also predicted by using the contact law as follows [13]:

$$
\begin{aligned}
& P=k \beta^{\frac{3}{2}} \\
& k=\frac{4}{3} E R^{\frac{1}{2}} \\
& \frac{1}{R}=\frac{1}{R_{1}}+\frac{1}{R_{2}} \\
& \frac{1}{E}=\frac{1-v_{1}^{2}}{E_{1}}+\frac{1-v_{2}^{2}}{E_{2}}
\end{aligned}
$$

where $k$ is the contact stiffness, $\beta$ is the indentation, $R_{1}$ and $R_{2}$ are the radii of curvature of the two objects, $E$ and $R$ are intermediate parameters, and $E_{1}, v_{1}$ and $E_{2}, v_{2}$ are the Young's moduli and Poisson's ratio of the two objects, respectively. It is worth noting that the above model was proposed for an impact event between two objects which have curved surfaces. However, the surface of RC beams and the projectile in most of the cases are flat. For such cases, the value of $R$ in Eq 7 becomes infinite and thus this model is inapplicable for predicting the impact force on $\mathrm{RC}$ beams. In addition, a simplified equation for the case of a spherical surface in contact with a flat surface was presented in the study by Lu and Yu [26], 
in which the Young's modulus and Poisson's ratio of the two objects were assumed to be the same. General cases of this contact problem with more details can be found in the book [26].

Meanwhile, the energy-balance model has been used by other researchers to predict impact force $[13,22,24,25]$. The initial kinetic energy of the projectile causes deformation of the structure during the impact event. Assuming that when the structure reaches its maximum deflection, the velocity of the projectile becomes zero and all initial kinetic energy is transferred to deform the structure. Accordingly, the energy-balance equation can be written as:

$$
\frac{1}{2} G V_{0}^{2}=E_{b}+E_{s}+E_{m}+E_{c}
$$

where $V_{0}$ is the initial velocity of the projectile, and $E_{b}, E_{s}, E_{m}, E_{c}$ are energies representing the bending deformation, shear deformation, membrane component, and indentation effect, respectively. The impact force can be estimated by the following equation

$$
P=V_{0}\left(k_{b s} G\right)^{\frac{1}{2}}
$$

where $k_{b s}$ is the linear stiffness including bending and transverse shear deformation effects. Eq 10 can be used to predict the impact force if the linear stiffness of RC beams is estimated. However, the linear stiffness of a structure does not necessarily remain constant during the impact and is not able to be simply estimated. For simplicity, regardless of the shear effects the linear stiffness of RC beams can be estimated in terms of the bending stiffness.

In general, the above models can be adopted to estimate impact force on RC beams. However, as discussed above, the application of these approaches is not straightforward and sometimes not possible. Pham and Hao [9] proposed a simple method using an artificial neural network to predict the impact force with the reasonable accuracy. Two models were proposed for 
predicting the impact force. They are a comprehensive model yielding high accuracy (about $10 \%$ error) and a simplified model with lower accuracy (about $23 \%$ error). The maximum impact force can be estimated by using the simplified model as follows:

$$
P=\sum_{i=1}^{6} p_{i} z_{i}-1119
$$

where $p_{i}$ is equal to $7.63,-0.02,1.93,-3.17,1.34,186.09$, respectively; and $z_{i}$ is the concrete strength, normalized bending stiffness, beam weight, overhang weight, projectile weight and impact velocity.

\section{Resulting moment and shear force}

To design RC beams against impact loads, dynamic shear force and resulting moment diagrams need to be determined. The shear force and resulting moment of $\mathrm{RC}$ beams against static loads can be easily drawn but forming these diagrams under impact loads is not a straightforward mission. The impact force, inertia force and its distribution need to be known before establishing the impact shear force and resulting moment diagrams at critical stages. When a projectile impacts a beam and accelerates it, the beam is then balanced by the participation of all force elements, such as impact force, reaction forces, and inertial forces. Experimental studies and numerical simulations have shown that the impact force is balanced primarily by the sum of the inertia force at the very early instant of the impact event $[1,4,5]$. Impact events usually occur in a very short period at about $1-2$ millisecond $[1,3,6]$. The impact force can be obtained by using the models presented previously while the inertia forces can be estimated by assuming its distribution and using the equation of equilibrium state. It is noted that at the maximum impact force, the reaction is negligible as observed in the study by Pham and Hao [3]. If the distribution of the inertia force is assumed to be linear, the resulting moment and shear force diagrams can be obtained as shown in Fig. 2. As shown, the resulting moment and shear force which affect the failure modes of RC beams are 
essentially dependent on the inertia force distribution, which is experimentally and numerically investigated in the subsequent sections.

\section{Plastic Hinge}

\section{Plastic hinge in steel beams}

The formation of plastic hinges in steel and concrete beams may be different. Plastic hinge formation in steel beams subjected to impact loads has been better studied than that in concrete beams and it is discussed here first. The similar phenomenon for RC beams will be discussed in the following section. When steel beams are excessively struck by a projectile, a plastic hinge may be formed and travel along the beams. The travelling hinge is an important concept which was first introduced by Lee and Symonds [27]. In general, the plastic hinge in a beam occurs when the maximum bending moment is equal to the full plastic bending moment of the beam that can be straightforwardly estimated given the beam cross section and material properties $[28,29]$. However, the formation and travelling of a plastic hinge are very difficult to be investigated during an impact event. A lot of efforts of researchers have been paid to verify the concept of the plastic hinge in impacted beams. In 1984, Symonds and Fleming [30] conducted a numerical investigation on the dynamic behavior of a beam subjected to impulsive loads and concluded that the concept of the travelling hinge is a fiction, without physical reality. However, other studies have confirmed the formation and propagation of the plastic hinge in metal beams subjected to impact loads [7, 28, 29, 31, 32]. Jones [7] summarized the impact behavior of a fully clamped beam impacted by a mass with the plastic hinge formation. The plastic hinge is defined to occur upon impact at the mid-span of the beam and travels with a velocity along the beam while the remainder of the beam is stationary. On the other hand, if a simply supported beam is impulsively loaded with a uniform load, plastic hinges originate at the support and travel toward the mid-span. It is 
noted that the inertia force is assumed to be only linearly distributed between the plastic hinges and it is negligible in the remainder of the beam [7]. If the plastic hinges reach the support, the travel time of a plastic hinge from the mid-span to the supports can be estimated by [7]:

$$
T_{1}=\frac{m G V_{0} L^{2}}{24 M_{0}(2 G+m L)}
$$

where $T_{1}$ is the travel time of a plastic hinge from the mid-span to the supports, $m$ is the mass per unit length of a beam, $G$ is the projectile weight, $V_{O}$ is the impact velocity, $L$ is the effective span, and $M_{0}$ is the plastic bending moment of the beam. It should be noted that this solution is obtained with an assumption that a plastic hinge develops underneath the impact point at $t=0$ [7]. Similarly, a complete solution for this problem can be also found in the book by Stronge and $\mathrm{Yu}$ [33], in which the authors assumed $t=0$ when the impact force is equal to the static collapse force. The static collapse force is the applied load which causes the plastic bending moment. In reality, however, a plastic hinge is formed only when the bending moment at that section exceeds the section capacity, i.e., the plastic bending moment of the section. Accordingly, the bending moment at the mid-span needs time to reach the value of the plastic bending moment. The plastic hinge at the mid-span therefore can only be formed after certain duration. The above assumptions in the previous studies [7, 33] are thus a simplification of the problem for the ease of subsequent plastic hinge propagation analysis. In addition, this problem was also solved by Johnson [29], in which the author assumed the inertia force is uniform along the beam. This assumption is different from the experimental results from RC beams. Therefore, these solutions may not yield good prediction for the impact behavior of RC beams. 
Considering a simply supported beam impacted by a projectile at mid-span, if the beam is relatively long such that the plastic hinge may not be able to reach the supports before the impact elapsed. In such cases, the inertia force only distributes within the two plastic hinges, instead of along the entire beam. Accordingly, determination of the location of a plastic hinge is important for forming the resulting moment and shear force distributions in the beam. The impact behavior of a beam struck by a mass can be divided into two phases separated by $t_{1}$. As discussed in the study by Jones [7], the shear effect likely governs the impact behavior of a beam during the period between the impact and $t_{1}$, where

$$
t_{1}=\frac{G V_{0}}{2 Q_{0}\left(1+\frac{G}{m \xi_{0}}\right)}
$$

Jones [7] provided a solution to estimate the location of a plastic hinge as follows:

$$
\xi_{0}=\frac{6 M_{0}}{Q_{0}}
$$

where $\xi_{o}$ is the location of the plastic hinge at $t_{1}$ and $Q_{0}$ is the plastic transverse shear force. If a beam is made of steel with yield stress $\sigma_{0}$, the plastic bending moment and shear force can be calculated by

$$
\begin{gathered}
M_{o}=\frac{\sigma_{0} h^{2}}{4} \\
Q_{o}=\frac{\sigma_{0} h}{2}
\end{gathered}
$$

where $h$ is the depth of cross section of the beam. In such cases, the location of the plastic hinge at the end of the first phase of motion can be estimated as $\xi_{0}=3 h$.

\section{Plastic hinge in concrete beams}


The formation of plastic hinges in concrete beams has not been well documented in the open literature yet. Cotsovos et al. [4] have proposed a definition of the effective length which is formed between two plastic hinges developed under impact. The authors suggested that the stress waves did not necessarily reach the supports during the very short impact period because of two reasons, namely the impact duration was nearly equal to or less than the necessary travel time for the stress wave reaching the supports; and excessive damage of concrete and yielding of reinforcement had absorbed part of the impact energy [4]. The authors attempted to identify the travelling time of the plastic hinge with the bending moment estimated from the static analysis. The formation of plastic hinges is assumed when cracks occur on the top face of the beam (negative moment). The authors assumed that the bending moment initiating cracks $\left(M_{c r}\right)$ is about 0.3 of the flexural capacity. It is noted that in the study the inertia force was observed but was not incorporated in the estimation of bending moment distribution. In a subsequent study, Cotsovos [5] estimated the bending moment initiating cracks by the equation below to improve the prediction accuracy:

$$
M_{c r}=\frac{f_{t} b h^{2}}{6}
$$

where $f_{t}$ is the tensile strength of concrete, $b$ and $h$ are the width and height of the beam section, respectively, The effective length is estimated by the following expression:

$$
\begin{aligned}
& L_{e f f}=2 v_{w} t_{1}^{*} \\
& v_{w}=\sqrt{\frac{G^{*}}{\rho}}
\end{aligned}
$$

where $L_{e f f}$ is the effective length, $v_{w}$ is the wave velocity, $G^{*}$ is the shear modulus, $t_{1}{ }^{*}$ is the required time for forming cracks at the upper face of the beam and $\rho$ is the concrete density. To incorporate the inertia force and considering the maximum impact force is resisted by the inertia force only between the plastic hinges, the bending moment is thus can be derived as 


$$
M=\frac{P L_{e f f}}{12}
$$

The travel time can be calculated as:

$$
t^{*}{ }_{1}=\sqrt{\frac{6 M_{c r}}{\dot{P} v_{w}}}
$$

where $\dot{P}=\frac{P}{t^{*}{ }_{1}}$ is the loading rate.

Therefore, if the maximum impact force is known, the location of the plastic hinges and the impact duration can be estimated. It should be noted that in the above derivation, it is assumed that the impact velocity is sufficiently large and impact duration sufficiently short such that during the action of impact loading the stress wave does not reach the supports, and hence the impact force is balanced completely by the inertial resistance of the beam.

As can be noted in the above discussions the formation of a plastic hinge, its location and its travel time were investigated by two different approaches. In addition, the definitions of the plastic hinge are also different in the two studies. To evaluate the performance of these approaches, reliable inertia force distribution is required.

\section{Inertia Force Distribution}

The inertia force distribution is experimentally investigated by using testing data from the study by Saatci and Vecchio [1]. In the tests, five accelerometers were fixed along the beams to monitor the acceleration at five points as presented in Fig. 3. The tested RC beams had a cross section of $250 \mathrm{~mm}$ in width, $410 \mathrm{~mm}$ in height and $4880 \mathrm{~mm}$ in length. Eight specimens, grouped in four pairs, were tested under simply supported conditions with a clear span of $3 \mathrm{~m}$. The tested specimens had similar longitudinal steel ratio and different transverse steel ratio, ranging from $0 \%$ to $0.3 \%$. The impact tests were conducted by using a drop-weight apparatus 
with multiple impacts. Each pair included two identical beams were tested under impact loads with two different schemes, denoted by the letters "a" and "b". Details of the testing setup and testing conditions are described in the study by Saatci and Vecchio [1]. Two different projectiles weighing $211 \mathrm{~kg}$ and $600 \mathrm{~kg}$ were used in the impact tests. The a-series specimens were first tested once with the smaller projectile $(211 \mathrm{~kg})$, followed by two impacts with the heavier projectile $(600 \mathrm{~kg})$. For b-series specimens, the testing order was reversed at which they were tested twice with the heavier projectile and the last one with smaller projectile.

The distributions of inertia forces along the four tested beams are obtained from the recorded accelerations at the five points along the beam and presented in Fig. 4. As can be seen from this figure, the whole beam was not significantly accelerated before $0.42 \mathrm{~ms}$. At about 0.83 ms, only the accelerations at Accelerometers 1 and 2 were prominent while other accelerometers were still almost not activated yet. At $1.25 \mathrm{~ms}$, the distribution of Accelerometers 1-4 was almost linear. Interestingly, at $1.25 \mathrm{~ms}$ the acceleration at Accelerometer 4 was equal or close to zero, which means that the portion beyond this point to the end of the beam was not accelerated yet. Meanwhile, it is worth noting that the impact duration of the tested beams was about $2 \mathrm{~ms}$. The impact force first increased to the peak at about $1 \mathrm{~ms}$ and reduced to zero at $2 \mathrm{~ms}$ with an approximately triangular shape. The impact duration of all tested beams is presented in Table 1. Therefore, at the maximum impact force only a part of the beam was accelerated and the distribution of the acceleration within this zone was approximately linear.

This observation can be explained by the plastic hinge theory $[7,28,31,32]$. When a projectile impacts a RC beam, a plastic hinge initiates at the mid-span of the beam and travels with a velocity towards the supports. The remainder of the beam portion before the arrival of the plastic hinge is stationary. Therefore only the activated portion of the beam will resist the 
impact load to maintain the dynamic equilibrium. Upon impact, a plastic hinge develops at the impact point quickly, and propagates away from the midspan to the supports with a velocity, as illustrated in Fig. 5 [28]. This study introduces the determination of the stationary point at which portion of the beam beyond this point has not been accelerated yet. Therefore, only a portion of the beam within the two stationary points is accelerated and the above experimental results confirmed that the distribution of the acceleration within this region is approximately linear. If the impact duration is very short, the plastic hinges may not reach the supports. In this case, only part of the beam is activated during the impact force duration to resist the impact load.

There has been a consensus that the peak moment and shear force in impacted beams occurred at very early stage of the impact $[1,3-6,34]$. The distribution of the inertia forces during that period is the main concern because impact force is balanced by the inertia force in the early stage of impact. From the experimental results presented by Saatci and Vecchio [1], the distribution of the inertia forces is summarized in Table 1. As can be seen, the impact force needed about 1-1.25 ms to reach the peak while the distribution of the inertia force is still approximately linear up to about $1.25 \mathrm{~ms}$ for all the tested beams. As a result, the assumption of linear distribution is valid. Most of existing studies investigating the impact behavior of RC beams adopted the linear distribution of the inertia force for the whole beam. However, the observation of the tested data indicates that the distribution of inertia force is linear only within the two stationary points. It is also noted that the plastic hinge location and the stationary point are different. This observation is confirmed by examining Fig. 6 presenting the formation of plastic hinges. It is noted that the plastic hinges were formed at about 1100 $\mathrm{mm}$ from the midspan. In order to further verify the distribution of inertia force, numerical simulations are carried out to confirm this observation from experimental results. 


\section{Numerical Verification}

\section{Numerical model}

To further examine the above observations of $\mathrm{RC}$ beams with different conditions and subjected to different impact loads, more data are needed. In this study a numerical model is developed to calculate the acceleration distribution along a RC beam under impact instead of performing laboratory tests. The numerical simulation was verified against the experimental results of a RC beam under impact loads presented in a previous study by Pham and Hao [3]. The simulation and testing results are compared to validate the simulation accuracy. Since the development of the numerical model is not the main concern of this study but utilized to investigate the inertia force distribution, the numerical model is only briefly presented for the brevity purpose.

The section of the tested rectangular RC beam was $150 \mathrm{~mm}$ in width and $250 \mathrm{~mm}$ in height. The beam was simply supported with the span of $1.9 \mathrm{~m}$. The experiment was conducted by using drop-weight apparatus including a projectile of $203.5 \mathrm{~kg}$ at a drop height of $2 \mathrm{~m}$. A detailed 3D finite element (FE) model was developed by using dynamic, non-linear, explicit analysis in LS-DYNA [35]. LS-DYNA has been widely employed to analyze problems associated with large deformation of structures subjected to high velocity impact and high strain rate behavior) of materials. It has been proven yielding reliable numerical predictions of structural response and damage to impact loadings. Mat_72Rel3 (MAT CONCRETE DAMAGE REL3, K\&C material model) in LS-DYNA was used to model concrete material. This material model considers the strain-rate effect, plasticity, and damage of softening after failure. The reliable predictions of the structural response of concrete structures against high load rate have been verified by a number of studies [36-38]. Reinforcements were modelled by using Piecewise-Linear-Plasticity model i.e. Mat_24 (MAT PIECEWISE LINEAR 
PLASTICITY), which has been proven reliable for the analysis of RC structure response under high load rates and yielded accurate results [36]. The empirical dynamic increase factor (DIF) for concrete and steel was used to estimate their dynamic strength at different strain rates [39]. The function MAT_ADD_EROSION is used to eliminate elements that do not further contribute to resisting the impact loads during the analysis. The AUTOMATIC SURFACE TO SURFACE contact algorithm in LS-DYNA was used to model the contact between the steel projectile/supports and the beam. The supports of the tested beam were modelled in detail including steel plates for load distribution and steel rollers. For boundary condition, the nodes of the outer steel plate were constrained in all directions. The initial velocity of the projectile was given as $6.26 \mathrm{~m} / \mathrm{s}$ as recorded in the experimental impact test. The model of the RC beam is presented in Fig. 7.

\section{Model verification}

The numerical simulation is verified against the experimental results obtained in the study by Pham and Hao [3]. The plastic strain in the RC beam is compared with the damage of the beams from the testing as shown in Fig. 8. High plastic strain occurs at the mid-span underneath the load cell, resulting in local damage in both the experiment and simulation. The failure mode is the combination of flexural and shear damage. Fig. 9 shows the mid-span displacement time history of the RC beam from simulation agrees well with that from the experiment. The maximum and residual displacements of the RC beam were $52 \mathrm{~mm}$ and 42 $\mathrm{mm}$, respectively. The corresponding results from the simulation are $52 \mathrm{~mm}$ and $45 \mathrm{~mm}$. These comparisons confirm the accuracy of the numerical model in simulating the dynamic responses of RC beams subjected to impact loads. The verified numerical model is then used to calculate the acceleration distribution along the $\mathrm{RC}$ beam subjected to drop-weight impact, and determine the inertia force distribution. 


\section{Inertia force distribution}

The acceleration from the simulation is examined at four points as presented in Fig. 10. The accelerations at these points at different time instants are presented in Fig. 11. The impact force of this beam needs $0.26 \mathrm{~ms}$ to reach the maximum value. The accelerations at these points are examined during this period. The numerical results show that the acceleration at Point 3 is still negligible at $0.18 \mathrm{~ms}$ after the impact. It means that the portion of the beam beyond this point has not been activated yet. At the instant of the maximum impact force $(0.26 \mathrm{~ms})$, the portion of the beam beyond $0.7 \mathrm{~m}$ from the mid-span is not accelerated yet. A stationary point can be assumed at about $0.7 \mathrm{~m}$ from the mid span. This observation together with experimental results presented previously proves that a plastic hinge does not necessarily reach the supports during the impact. In a previous study Cotsovos et al. [4] also presented numerical simulations and concluded that stress waves generated by the impact force at midspan were unable to reach the supports within the short impact duration. Only a portion of the beam between the stationary points is accelerated while the rest of the beam has not been activated yet.

\section{Determination of Plastic Hinge Location and Travel Time}

The plastic hinge location and its travel time are needed to characterize the beam responses. It is well known that/a plastic hinge is formed when reinforcement yields and concrete reaches its strength limit. The plastic hinge then cannot receive higher bending moment so that this threshold value is determined as a plastic bending moment [40]. By adopting this definition, this study assumes that a plastic hinge in RC beam is formed when the moment at that section reaches the dynamic bending moment capacity $\left(M_{u d}\right)$, in which the strain rate effect is taken into account. The dynamic increase factor for steel and concrete is recommended as 1.23 and 1.25, respectively [41]. The position of plastic hinges and distribution of inertia force are 
sketched in Fig. 12. Once a plastic hinge reaches Point A at the maximum impact force, the farthest point that has been accelerated is at Point B (stationary point). It is noted that since the velocity linearly relates to the acceleration, the distribution of the velocity response along the beam is therefore also linear. Assuming velocity of the projectile at the maximum impact force is $v_{m}$, the conservation of momentum yields

$$
G\left(V_{0}-v_{m}\right)=2 m \frac{x_{0}}{2} v_{m}=m x_{0} v_{m}
$$

This equation is identical to Eq. 10 which has two unknowns $x_{0}$ and $v_{m}$. In addition, the total energies of the projectile and beam at the peak impact force must be/equal to the impact energy. By consideration of the conservation of energies, the following equation can be obtained at the peak impact force

$$
\Delta E=E_{e}+E_{\mathrm{ker}}+E_{b}
$$

where $\Delta E$ is the difference in the kinetic energies of the projectile, $E_{e}$ is the energy loss in the form of vibrations and elastic/plastic strain energy, $E_{k e r}$ is the rotational kinetic energy of the accelerated parts of the specimen, and $E_{b}$ is the bending energy in the specimen. The bending energy, estimated from the area under the force - displacement curve, consists of the elastic strain energy and the work of fracture. Details about determination of these energies can be found in the study by Banthia et al. [42]. Since the distribution of the velocity along the beam is linear $[7,42]$, the kinetic energy of the accelerated parts of the beam can then be calculated by

$$
E_{\mathrm{ker}}=m x_{0} v_{m}^{2}
$$

Banthia et al. [42] conducted experimental tests on 36 beams which were $100 \mathrm{~mm}$ x $125 \mathrm{~mm}$ in cross section and $1400 \mathrm{~mm}$ in length. These include 19 beams made of normal strength concrete (42 $\mathrm{MPa})$ and 17 beams made of high strength concrete (82 MPa). The authors 
concluded that the energy absorbed by the beam is only a small portion of the energy lost by the projectile. Without loss of generality, it can be assumed that the energy absorbed by the beam is equal to a portion $(\alpha)$ of the energy lost by the projectile at the maximum impact force, the following equation is obtained

$$
E_{\mathrm{ker}}=\alpha \Delta E
$$

By solving Eqs. 22- 25, the position of the stationary point (Point B) in Fig. 12 and velocity of the projectile at the maximum impact force can be calculated as follows

$$
\begin{aligned}
& x_{0}=\frac{G}{m}\left(\frac{1}{2 \alpha}-2\right) \\
& v_{m}=\frac{2 \alpha V_{0}}{1-2 \alpha}
\end{aligned}
$$

To identify the percentage of energy absorbed in a beam at the maximum impact force, Banthia et al. [42] conducted impact/tests and evaluated the composition of the above energies as presented in Fig. 13. It can be seen that the bending energy is about $21 \%$ of the energy by the projectile. A similar observation is also found for high strength concrete in which the corresponding ratio was $19 \%$. Since the present study deals with normal strength concrete, it is thus reasonable to assume that at the maximum impact force the bending energy of the beam is about $21 \%$ of the energy lost by the projectile. The position of the stationary point (Point B) can be calculated by the proposed procedure and the result is compared to those in the experimental tests in [1,3]. The comparison of the predicted results and experimental/numerical results is presented in Fig. 14. The predictions are in agreement with the experimental/numerical results, in which the performance of the velocity prediction is better than that of the position of the stationary point. Since the proposed procedure can 
predict reasonably the position of the stationary points and velocity at the maximum impact force, it can be used to generate the shear force and bending diagrams.

\section{Shear Force and Bending Moment Diagrams}

By interpreting experimental and numerical results, it can be seen that plastic hinges may not reach the beam supports during an impact event. The inertia force distribution is confirmed to be approximately linear within two stationary points. If the location of the plastic hinges and the stationary points are not determined, the inertia force is usually assumed to distribute on the whole beams. In such cases, the shear forces and resulting bending moment diagrams may not be appropriately built. Once the position of the stationary point and then the inertia force distribution is well predicted, the shear forces and resulting bending moment diagrams can be accurately derived. The maximum impact force can be estimated by adopting any model as reviewed previously. The position of the stationary point is estimated by using Eq. 26. The position of the plastic hinges (Point A) is estimated from the plastic bending moment and the position of the stationary point (Point B) by using Eq. 28.

$$
x_{A}=x_{0}-\sqrt[3]{\frac{6 M_{0} x_{0}^{2}}{P}}
$$

where $M_{0}$ is the plastic bending moment of the beam.

For RC beams, a plastic hinge is assumed to form when the tension reinforcement yields. This moment at the plastic hinge is a constant and can be taken equal to the section nominal bending moment [35]. A procedure for generating the shear force and bending moment diagrams is shown in Fig. 15.

\section{Parametric Study}


It should be noted that the above results and observations are based on experimental and numerical results of $\mathrm{RC}$ beams subjected to a constant impact velocity of the respective study. Since the inertia force distribution in a beam and the time required for the impact force to reach its peak value should be highly dependent on the impact velocity, the above results and observations are impact velocity dependent. For example, when the impact velocity is slow, the reaction force should be activated to resist the impact force, like a beam under quasi-static loading. In such cases the contribution of inertia force will be relatively less significant. On the other hand, when the impact velocity is large, the projectile might penetrate through the beam. Therefore the response and damage mode of the beam is very different. Under those conditions the above derived formulae are no longer valid and meaningful. In order to define the applicable range of the proposed procedure and the assumption of the linear inertia force distribution, a parametric study was carried out based on the numerical simulations in this study. The dimension and design of the beams remain unchanged while the impact velocity varies from $1 \mathrm{~m} / \mathrm{s}$ to $12 \mathrm{~m} / \mathrm{s}$. The numerical simulation results show that the linear inertia force distribution assumption during the impact loading phase up to the peak impact force is valid for the impact velocity from $3 \mathrm{~m} / \mathrm{s}$ to $12 \mathrm{~m} / \mathrm{s}$. When the impact velocity is less than 3 $\mathrm{m} / \mathrm{s}$, the linear distribution assumption of the inertia force is no longer correct. It is noted that when the impact velocity is less than $3 \mathrm{~m} / \mathrm{s}$ the time history of the impact force does not exhibit a sharp increase to its peak, and the beam response is governed by the global flexural response, whereas the local or combined local and global response is more dominant to the beam response when the impact velocity is relatively high. Therefore the linear inertia force distribution assumption is valid only when the impact velocity is higher than $3 \mathrm{~m} / \mathrm{s}$.

The numerical simulations are also used to examine the applicability of the above proposed formulae in predicting the position of the stationary point. The numerical simulation results confirm that the position of the stationary points of the beams depends on the impact velocity, 
and varies from $750 \mathrm{~mm}$ to $600 \mathrm{~mm}$ from the mid span when the impact velocity varies from $3 \mathrm{~m} / \mathrm{s}$ to $9 \mathrm{~m} / \mathrm{s}$. When the impact velocity is greater than $9 \mathrm{~m} / \mathrm{s}$, the stationary point is close to the midspan underneath the drop weight, which therefore is not predicted well by the proposed procedure. The position of the stationary points is approximately between $400 \mathrm{~mm}$ and $300 \mathrm{~mm}$ from the midspan when the impact velocities range from $10 \mathrm{~m} / \mathrm{s}$ to $12 \mathrm{~m} / \mathrm{s}$. In such cases, the punching shear damage is more dominant to the failure, leading to a smaller effect from the global beam response, thus the bending moment is not critical In addition, since the shear mechanism may govern the failure, the percentage of the lost energy transferring to accelerate the beam $(\alpha)$ is possibly changed, which could be another deficient in the prediction. The higher the impact velocity, the position of the stationary point is closer to the midspan. Therefore the proposed procedure in this study may not yield accurate prediction if the impact velocity is either less than $3 \mathrm{~m} / \mathrm{s}$ or greater than $9 \mathrm{~m} / \mathrm{s}$. It should be noted that other parameters such as the drop weight, beam dimension and beam stiffness should also affect the above observations besides impact velocity. More parametric studies are therefore deemed necessarily for better understanding this complex problem.

\section{Conclusion}

This study has examined the formation of plastic hinges and the inertia force distribution in RC beams under impact. From the experimental/numerical results and the analyses, the following findings can be drawn:

1. The distribution of inertia forces in a beam is linear up to the maximum impact force. This observation is valid for the impact velocity from $3 \mathrm{~m} / \mathrm{s}$ to $12 \mathrm{~m} / \mathrm{s}$ for the considered drop weight and RC beams in this study. This observation has been verified versus experimental and numerical results and it can be used for deriving shear force and bending moment diagrams. 
2. Plastic hinges may develop and travel from the mid-span of a beam to the supports and its position significantly affects the impact behaviour of the beam. An analytical formula is developed to predict the plastic hinge position in this study, which is valid for the impact and beam conditions considered in the present study in the impact velocity range of $3 \mathrm{~m} / \mathrm{s}$ to $9 \mathrm{~m} / \mathrm{s}$.

3. If a plastic hinge does not reach a support, only a part of the beam within the stationary points is accelerated. The rest of the beam is still stationary.

4. The proposed procedure can be used to predict the position of the plastic hinge and the velocity of the mid-span at the maximum impact force.

The impact behavior of a RC beam is very complicated. More studies are deemed necessary for better understanding of this sophisticated problem.

\section{Notation}

The following symbols are used in this paper:

$E \quad=$ intermediate Young modulus;

$E_{1} \quad=$ Young modulus of object 1

$E_{2} \quad=$ Young modulus of object 2;

$E_{b} \quad=$ energy represents the bending deformation;

$E_{c} \quad=$ energy represents the indentation effect;

$E_{e} \quad=$ energy lost to the various equipment;

$E_{k e r}=$ rotationalkinetic energy of the accelerated parts of the specimen;

$E_{m} \quad=$ energy represents the membrane component;

$E_{s} \quad=$ energy represents the shear deformation;

$G \quad=$ projectile weight;

$G^{*} \quad=$ shear modulus of concrete;

$G_{0}=$ plastic shear capacity;

$G_{1}=$ projectile weight;

$G_{2} \quad=$ structure weight;

$L$ = beam span;

$L_{\text {eff }} \quad=$ effective span defined by Cotsovos [5];

$M$ = bending moment;

$M_{0} \quad=$ plastic bending moment;

$M_{c r}=$ cracking moment in a RC beam;

$M_{u d}=$ ultimate bending moment under dynamic loads;

$P \quad=$ maximum impact force;

$R \quad=$ intermediate radius; 
$R_{1} \quad=$ radius of object 1

$R_{2} \quad$ = radius of object 2 ;

$T_{1} \quad=$ travel time of a plastic hinge from the mid-span to the supports;

$V_{0} \quad$ impact velocity;

$b \quad=$ width of the section;

$f_{t} \quad=$ tensile strength of concrete;

$h \quad=$ height of the section;

$k \quad=$ contact stiffness;

$k_{1} \quad=$ local indentation stiffness;

$k_{2} \quad=$ structure stiffness;

$k_{b} \quad=$ flexural bending stiffness;

$k_{b s} \quad=$ linear stiffness including bending and transverse shear deformation effects;

$k_{m} \quad=$ membrane effect stiffness;

$m \quad$ = mass per unit length of a beam;

$t_{1} \quad=$ duration for the impact force reaches its maximum value;

$t_{1}{ }^{*}=$ required time for forming cracks at the upper face of the beam;

$v_{m} \quad=$ velocity at mid-span at time $T_{1}$;

$v_{w} \quad=$ velocity of the shear stress wave;

$x \quad=$ movement of the structure;

$x_{0} \quad=$ position of Point B in Fig. 12;

$x_{1} \quad=$ movement of the projectile;

$x_{2}=$ movement of the structure;

$x_{A} \quad=$ position of plastic hinge defined by this study;

$\alpha=$ portion of kinetic energy transfers from a projectíle to a beam;

$\beta \quad=$ indentation of a beam;

$\Delta E \quad=$ energy lost by the projectile at time $T_{1}$;

$v_{l} \quad=$ Poisson's ratio of object 1 ;

$v_{2} \quad=$ Poisson's ratio of object 2 ;

$\xi_{0} \quad=$ position of a plastic hinge in the solution by Jones [7];

$\rho \quad=$ concrete density; and

$\sigma_{0} \quad=$ yielding stress.

\section{References}

[1] Saatci S and Vecchio FJ, Effects of shear mechanisms on impact behavior of reinforced concrete beams, ACI Struct J 2009;106 (1):78-86.

[2] Kishi N, Mikami H, Matsuoka K, and Ando T, Impact behavior of shear-failure-type RC beams without shear rebar, Int J Impact Eng 2002;27 (9):955-968.

[3] Pham TM and Hao H, Behavior of Fiber Reinforced Polymer Strengthened Reinforced Concrete Beams under Static and Impact Loads, Int J Prot Struct 2016;DOI: 10.1177/2041419616658730.

[4] Cotsovos D, Stathopoulos N, and Zeris C, Behavior of RC beams subjected to high rates of concentrated loading, J Struct Eng 2008;134 (12):1839-1851.

[5] Cotsovos DM, A simplified approach for assessing the load-carrying capacity of reinforced concrete beams under concentrated load applied at high rates, Int J Impact Eng 2010;37 (8):907-917.

[6] Pham TM and Hao H, Impact Behavior of FRP-Strengthened RC Beams without Stirrups, J Compos Constr 2016;20 (4):04016011.

[7] Jones N, Structural impact, Cambridge university press, 2011. 
[8] Banthia N, Mindess S, Bentur A, and Pigeon M, Impact testing of concrete using a dropweight impact machine, Exp Mech 1989;29 (1):63-69.

[9] Pham TM and Hao H, Prediction of the Impact Force on RC Beams from a Drop Weight, Adv Struct Eng 2016;DOI: 10.1177/1369433216649384.

[10] Bhatti AQ, Kishi N, Mikami H, and Ando T, Elasto-plastic impact response analysis of shear-failure-type RC beams with shear rebars, Mater Design 2009;30 (3):502-510.

[11] Bischoff PH, Perry SH, and Eibl J, Contact force calculations with a simple spring-mass model for hard impact: A case study using polystyrene aggregate concrete, Int J Impact Eng 1990;9 (3):317-325.

[12] Wu KQ and Yu TX, Simple dynamic models of elastic-plastic structures under impact, Int J Impact Eng 2001;25 (8):735-754.

[13] Abrate S, Modeling of impacts on composite structures, Compos Struct 2001;51 (2):129138.

[14] Alves $\mathrm{Ml}$ and Jones $\mathrm{N}$, Impact failure of beams using damage mechanics: Part IAnalytical model, Int J Impact Eng 2002;27 (8):837-861.

[15] Hao H, Predictions of Structural Response to Dynamic Loads of Different Loading Rates, Int J Prot Struct 2015;6 (4):585-606.

[16] Fujikake K, Li B, and Soeun S, Impact response of reinforced concrete beam and its analytical evaluation, J Struct Eng 2009;135 (8):938-950.

[17] Pham TM and Hao H, Review of Concrete Structures Strengthened with FRP against Impact Loads, Struct 2016;7:59-70.

[18] Shivakumar K, Elber W, and Illg W, Prediction of impact force and duration due to lowvelocity impact on circular composite laminates, J Appl Mech 1985;52 (3):674-680.

[19] Delfosse D and Poursartip A, Energy-based approach to impact damage in CFRP laminates, Compos Par A-Appl S 1997;28 (7):647-655.

[20] Olsson R, Engineering method for prediction of impact response and damage in sandwich panels, Journal of Sandwich Structures and Materials 2002;4 (1):3-29.

[21] Olsson R, Analytical prediction of large mass impact damage in composite laminates, Compos Par A-Appl S 2001;32 (9):1207-1215.

[22] Zhou D and Stronge W, Low velocity impact denting of HSSA lightweight sandwich panel, Int J Mech Sci 2006;48 (10):1031-1045.

[23] Lifshitz J, Gov F, and Gandelsman M, Instrumented low-velocity impact of CFRP beams, Int J Impact Eng 1995;16 (2):201-215.

[24] Hazizan MA and Cantwell W, The low velocity impact response of an aluminium honeycomb sandwich structure, Compos Part B 2003;34 (8):679-687.

[25] Foo CC, Seah LK, and Chai GB, A modified energy-balance model to predict lowvelocity impact response for sandwich composites, Compos Struct 2011;93 (5):1385-1393.

[26] Lu G and Yu T, Energy absorption of structures and materials, Elsevier, 2003.

[27] Lee E and Symonds PS, Large plastic deformations of beams under transverse impact, J Appl Mech 1952;19 (3):308-314.

[28] Yu T, Yang J, and Reid S, Interaction between reflected elastic flexural waves and a plastic 'hinge' in the dynamic response of pulse loaded beams, Int J Impact Eng 1997;19 (5):457-475.

[29] Johnson W, Impact strength of materials, Edward Arnold London, 1972.

[30] Symonds PS and Fleming W, Parkes revisited: on rigid-plastic and elastic-plastic dynamic structural analysis, Int J Impact Eng 1984;2 (1):1-36.

[31] Yu T and Chen F, A further study of plastic shear failure of impulsively loaded clamped beams, Int J Impact Eng 2000;24 (6):613-629.

[32] Liu J and Jones N, Dynamic response of a rigid plastic clamped beam struck by a mass at any point on the span, International journal of solids and structures 1988;24 (3):251-270. 
[33] Stronge WJ and Yu T, Dynamic models for structural plasticity, Springer Science \& Business Media, 1993.

[34] Menkes S and Opat H, Broken beams, Exp Mech 1973;13 (11):480-486.

[35] LS-Dyna, keyword user's manual V971, 2Livermore Technology Software Corporation, Livermore, CA 2012:2994.

[36] Yonten K, Manzari MT, Eskandarian A, and Marzougui D, An evaluation of constitutive models of concrete in lsdyna finite element code, in: 15th ASCE Engineering Mechanics Conference, Columbia University, New York, NY, 2002.

[37] Malvar LJ, Crawford JE, Wesevich JW, and Simons D, A plasticity concrete material model for DYNA3D, Int J Impact Eng 1997;19 (9):847-873.

[38] Chen W, Hao H, and Chen S, Numerical analysis of prestressed reinforced concrete beam subjected to blast loading, Mater Design 2015;65:662-674.

[39] Hao Y and Hao H, Influence of the concrete DIF model on the numerical predictions of RC wall responses to blast loadings, Eng Struct 2014;73:24-38.

[40] MacGregor JG, Reinforced concrete: mechanics and design, Prentice Hall, Upper Saddle River, N.J, 2005.

[41] fib, fib Model Code for Concrete Structures, in, Switzerland, 2010.

[42] Banthia N, Mindess S, and Bentur A, Energy balance in instrumented impact tests on plain concrete beams, in: Fracture of Concrete and Rock, Springer, 1989, pp. 26-36. 


\section{List of Figures}

Figure 1. Spring-mass models

Figure 2. Bending moment and shear force diagrams under impact

Figure 3. Position of accelerometers

Figure 4. Distribution of acceleration along a RC beam

Figure 5. Formation of plastic hinges in $\mathrm{RC}$ beams

Figure 6. Plastic hinges in RC beams

Figure 7. Modelling of the RC beam

Figure 8. Plastic strain of the RC beam

Figure 9. Mid-span displacement from the simulation vs experiment

Figure 10. Monitoring acceleration points

Figure 11. Distribution of acceleration along RC beams - numerical results

Figure 12. Formation of plastic hinges and inertia forces

Figure 13. Evaluation of energies (normal strength concrete)

Figure 14. Comparison between prediction vs experiment

Figure 15. Flow chart of determination of the shear force and bending moment diagrams 


\section{List of Tables}

Table 1. Test matrix

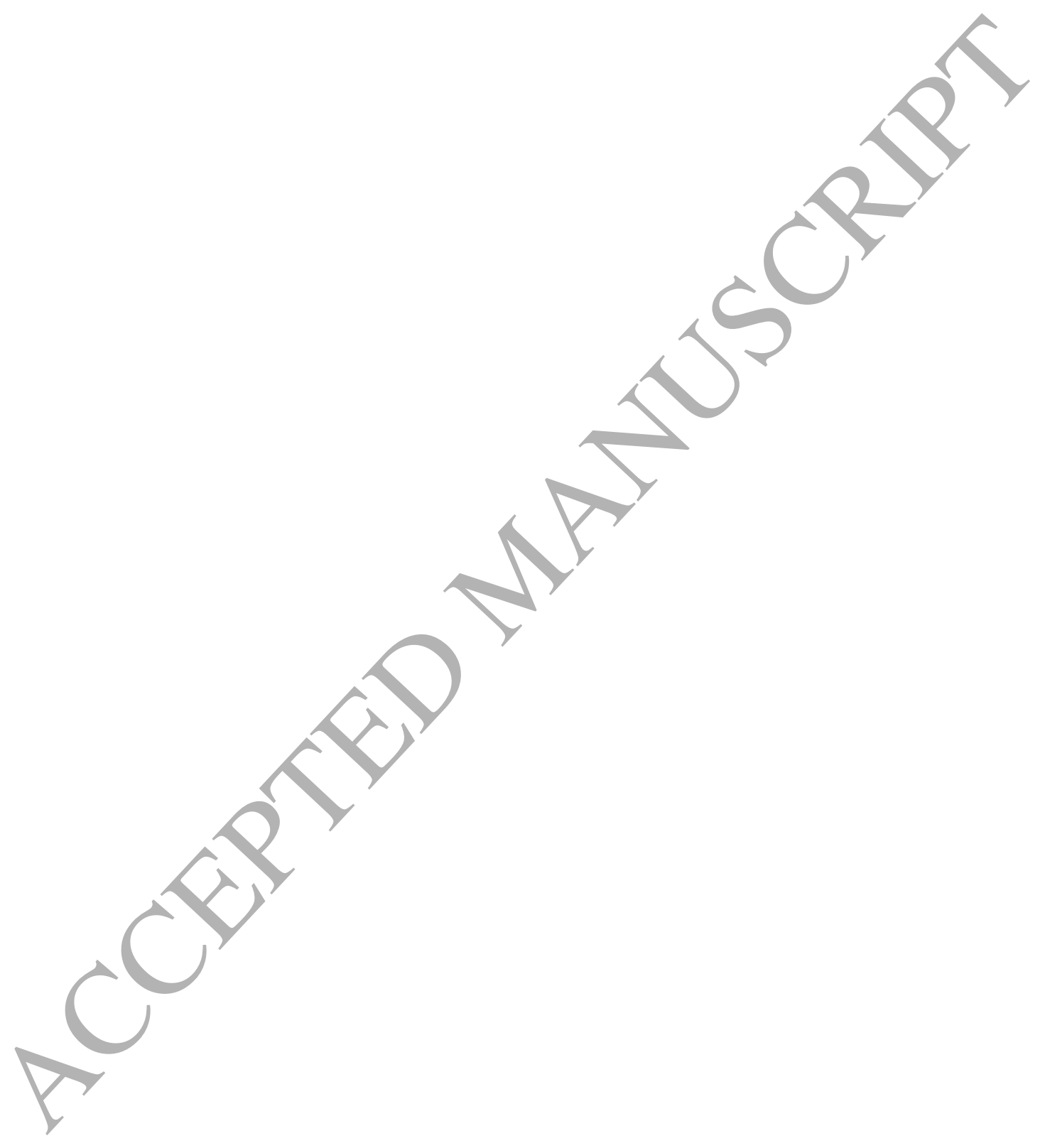


Table 1. Experimental results of the impact tests

\begin{tabular}{|c|c|c|c|c|}
\hline Beams & $\begin{array}{l}\text { Time } \\
(\mathrm{ms})\end{array}$ & $\begin{array}{c}\text { Max } \\
\text { acceleration }(\mathrm{g})\end{array}$ & $\begin{array}{c}\text { Impact } \\
\text { duration }(\mathrm{ms})\end{array}$ & $\begin{array}{l}\text { Plastic } \\
\text { hinge }\end{array}$ \\
\hline SS0a_1 & 1.25 & 170 & - & - \\
\hline SSOb_1 & 1.25 & 410 & 2.5 & - \\
\hline SS1a_1 & 1.25 & 300 & 2 & - \\
\hline SS1a_2 & 1.25 & 420 & 2 & Yes \\
\hline SS1a_3 & 2.08 & 600 & 3 & Yes \\
\hline SS1b_1 & 1.25 & 650 & & \\
\hline SS1b_2 & 1.67 & 800 & 3.5 & \\
\hline SS2a_1 & 1.67 & 450 & 2 & \\
\hline SS2a_2 & 1.67 & 400 & 2 & \\
\hline SS2a_3 & 1.67 & 1000 & 3 & Yes \\
\hline SS2b_1 & 1.25 & 740 & & - \\
\hline SS2b_2 & 1.25 & 720 & & Yes \\
\hline SS2b_3 & 2.08 & 450 & 3 & Yes \\
\hline SS3a_1 & 1.67 & 370 & 2 & - \\
\hline SS3a_2 & 1.67 & 750 & 2 & Yes \\
\hline SS3a_3 & 1.67 & 440 & - & - \\
\hline SS3b_1 & 1.25 & 700 & 1.5 & - \\
\hline SS3b_2 & 1.67 & 350 & 4 & - \\
\hline SS3b_3 & 1.67 & 56 & 2 & Yes \\
\hline
\end{tabular}

- Not applicable 
Fig. 1
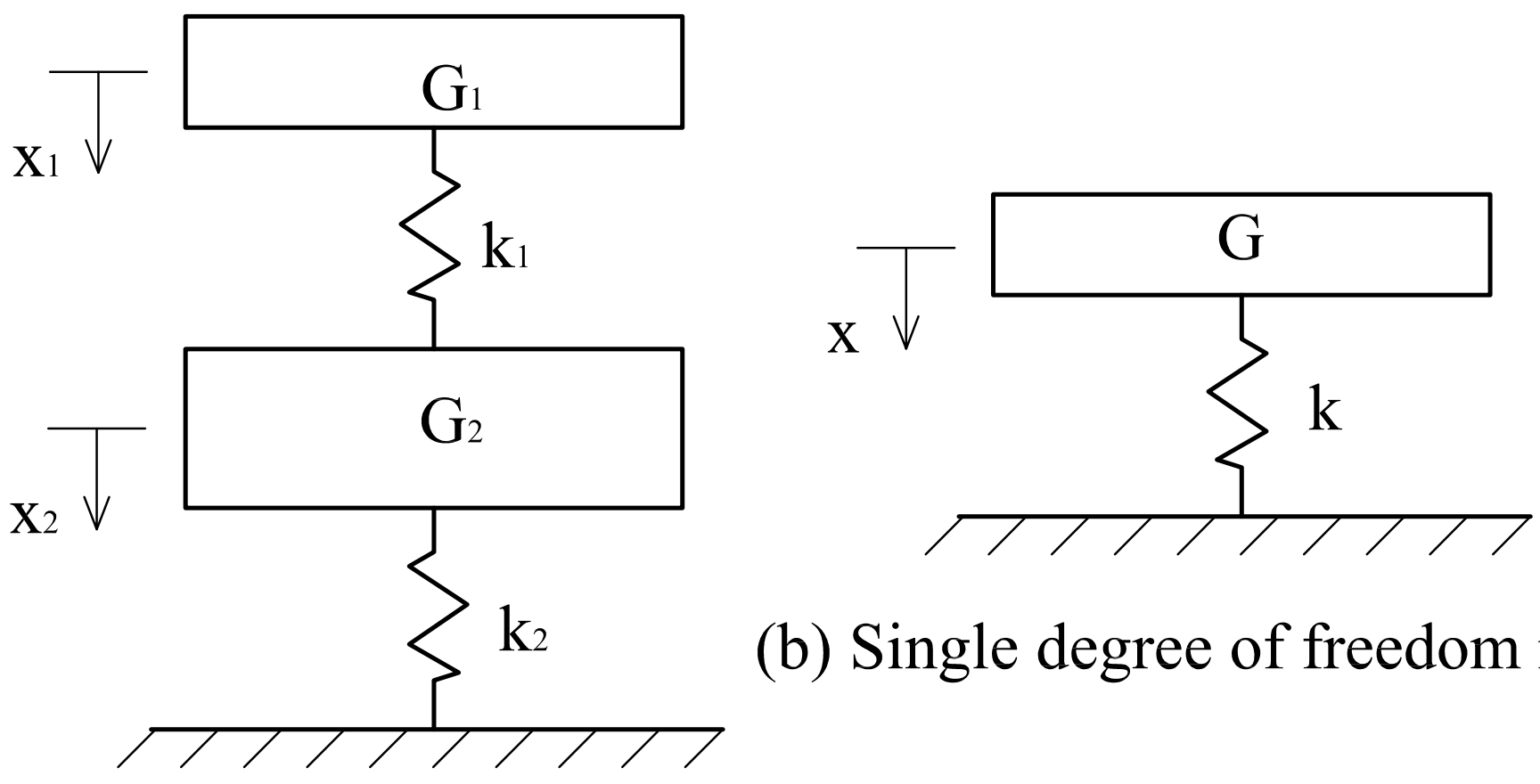

(b) Single degree of freedom model

(a) Two degree of freedom model 
Fig. 2
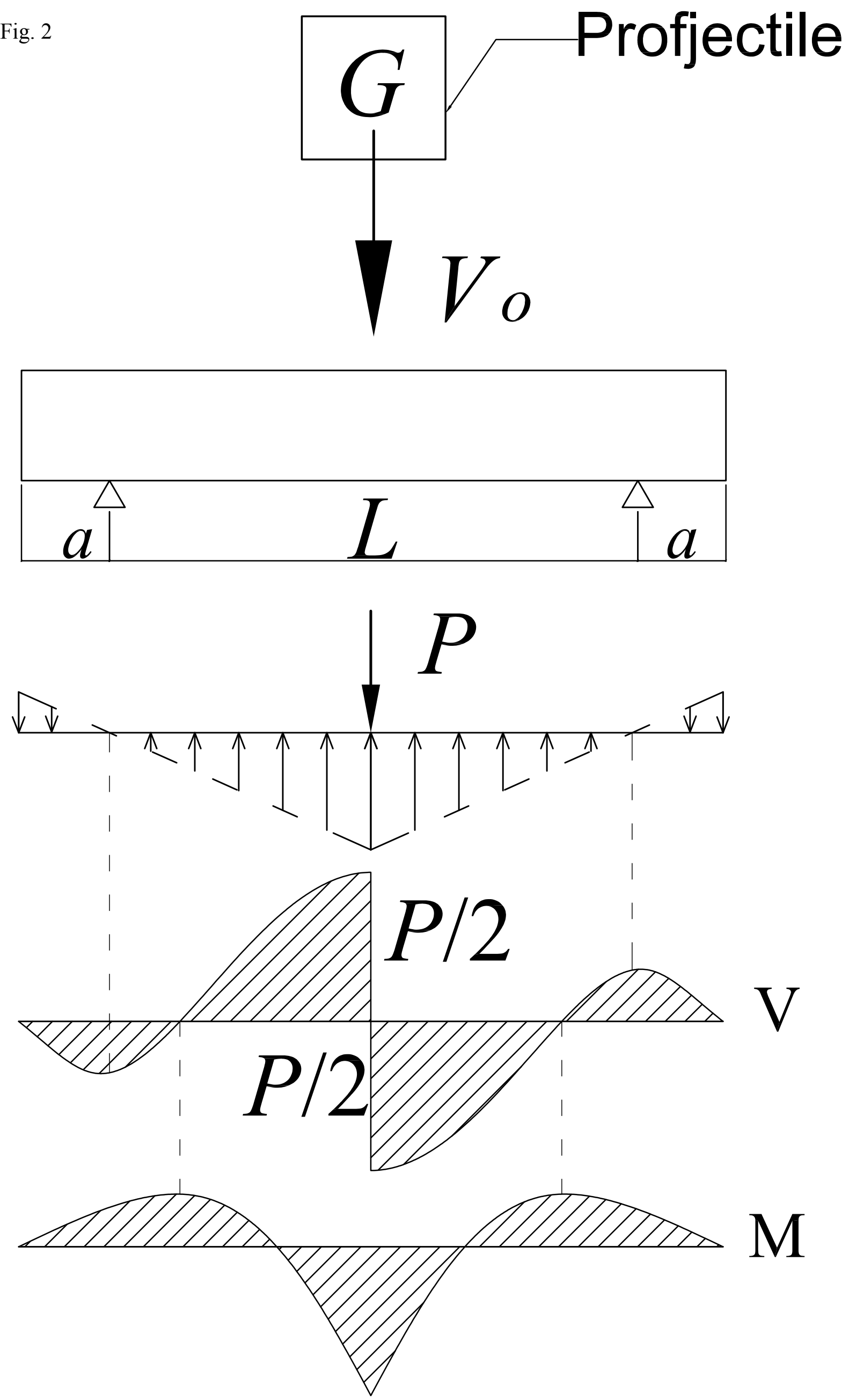

$$
M=\underset{L\left(1-4 a^{2} / L^{2}\right)}{P}\left(L^{2} / 12-a^{2}-4 a^{3} / 3 L\right)
$$


Fig. 3

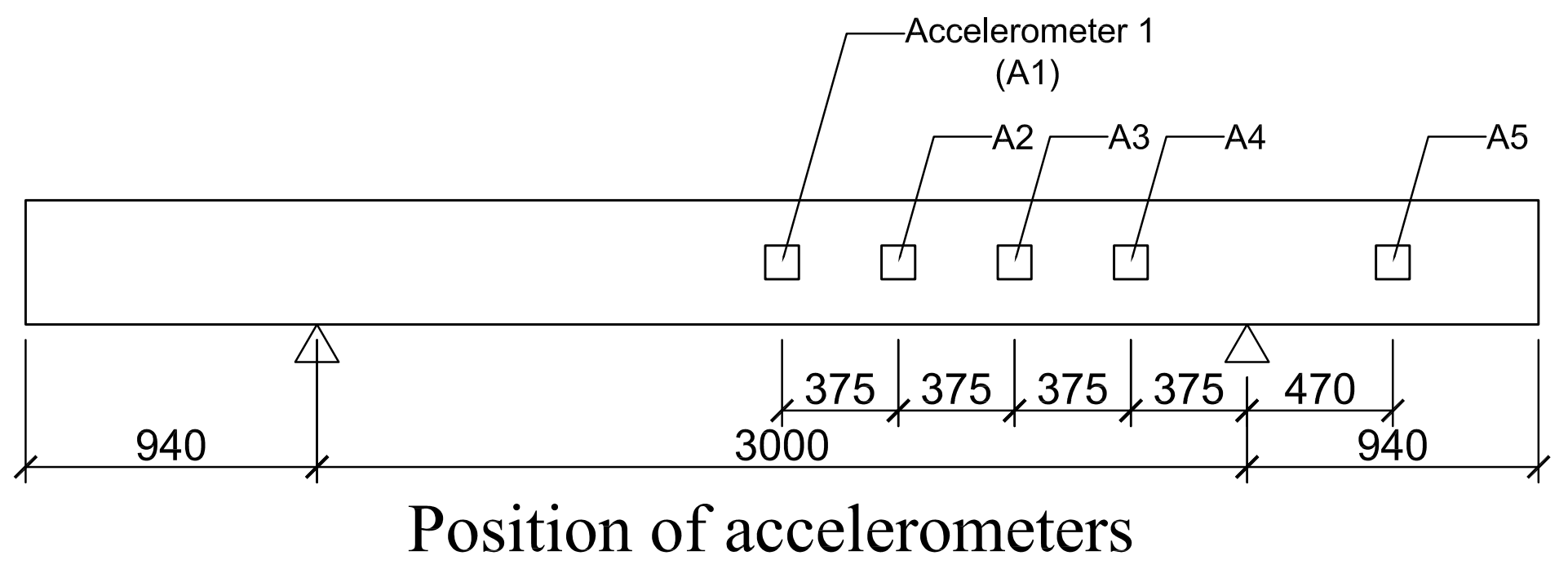


Fig. 4

Specimen SS0a 1
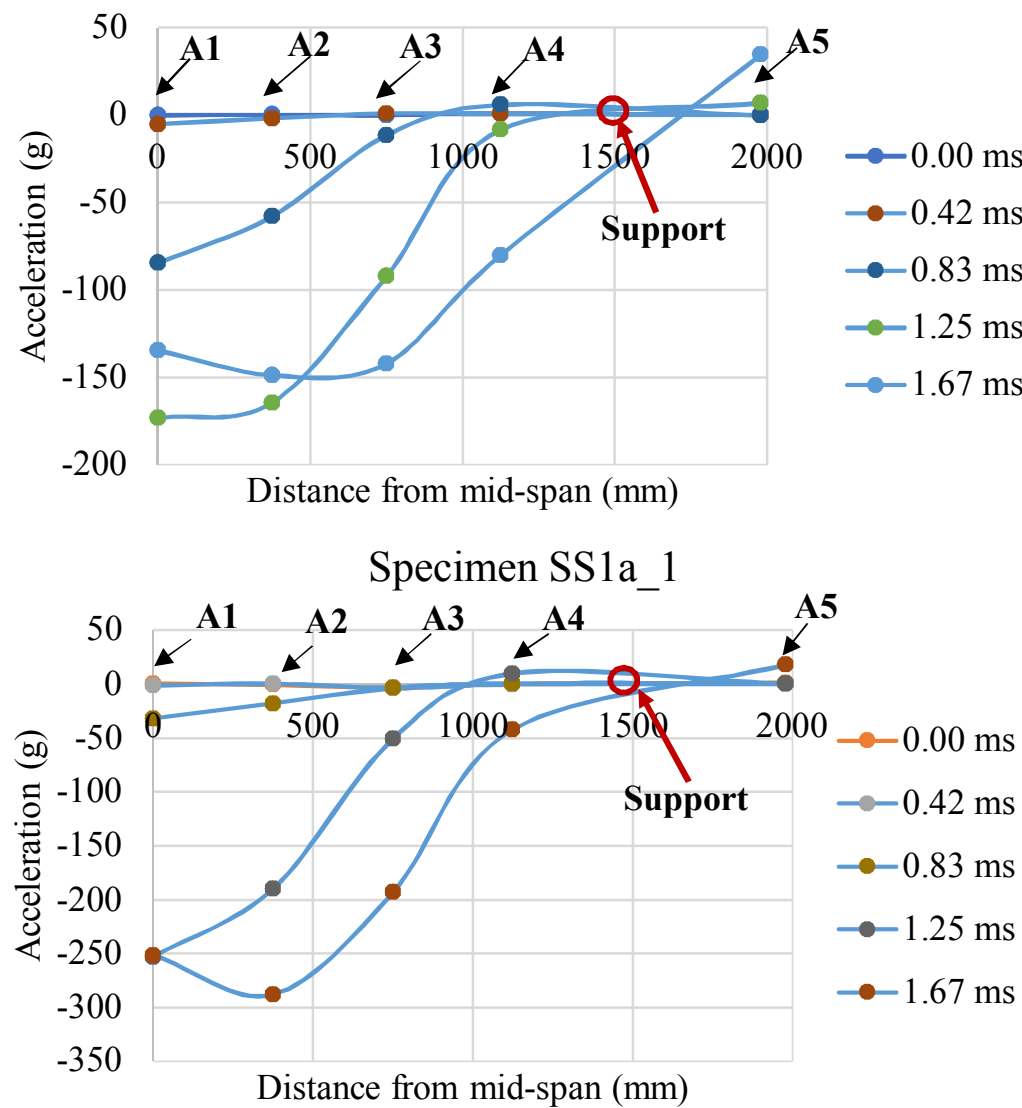

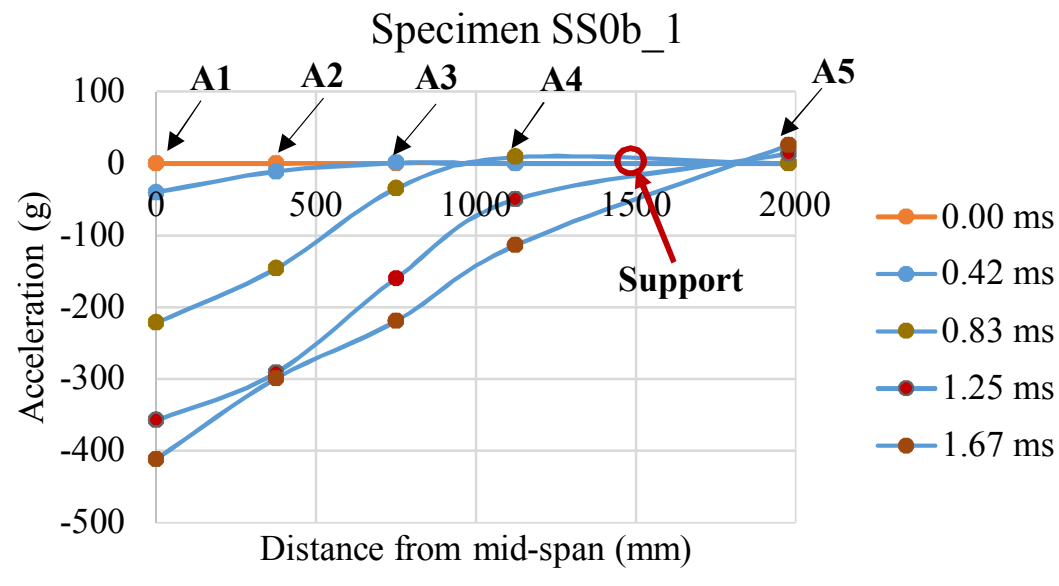

Specimen SS1b_1

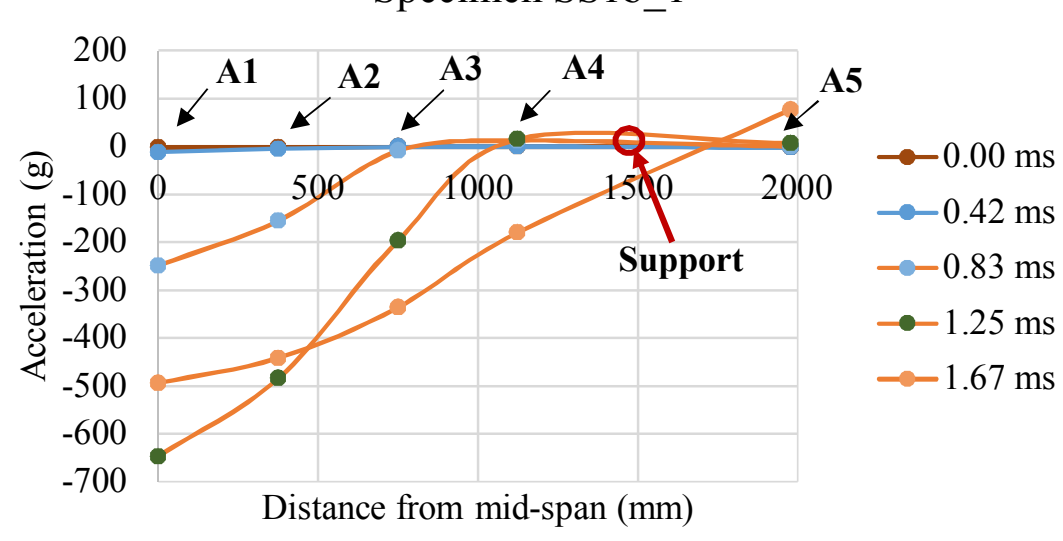


Fig. 5
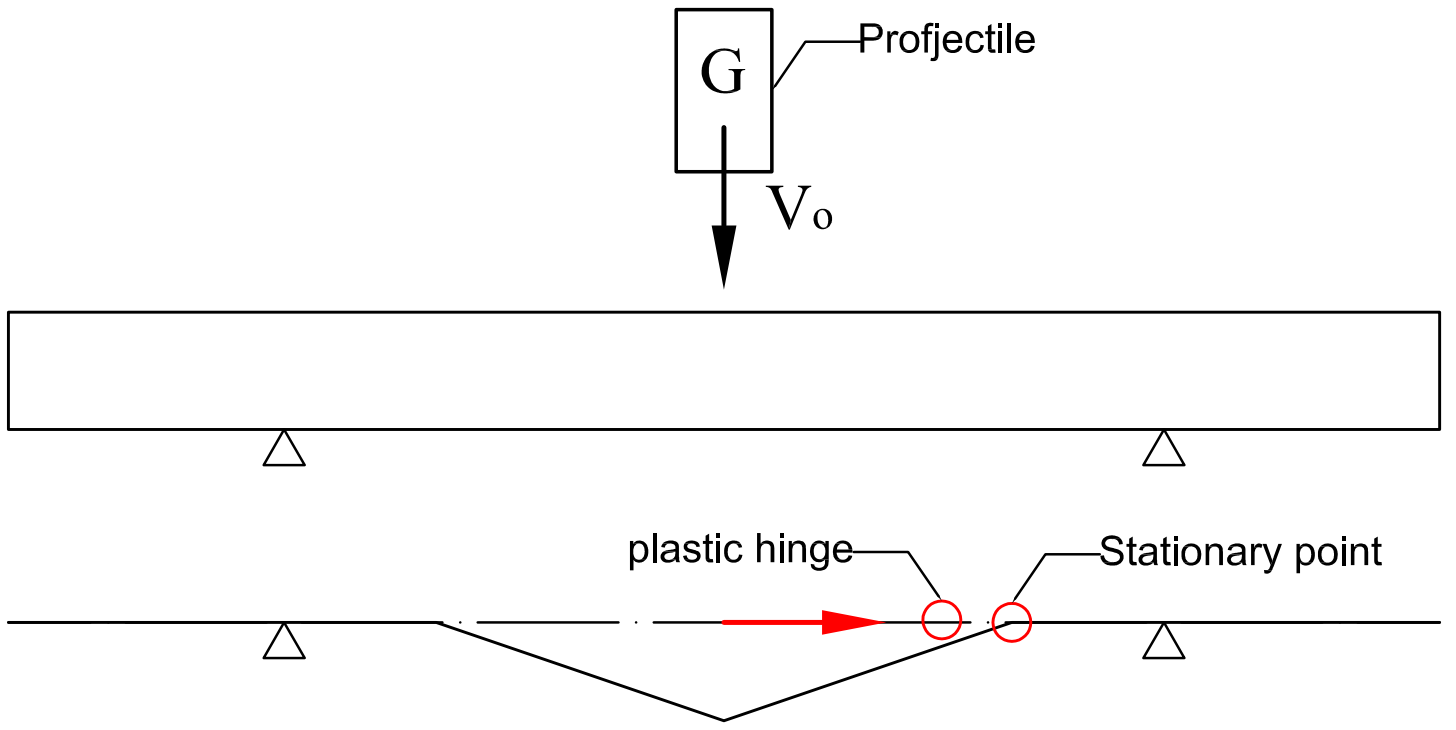

Formation of plastic hinges 
Fig. 6
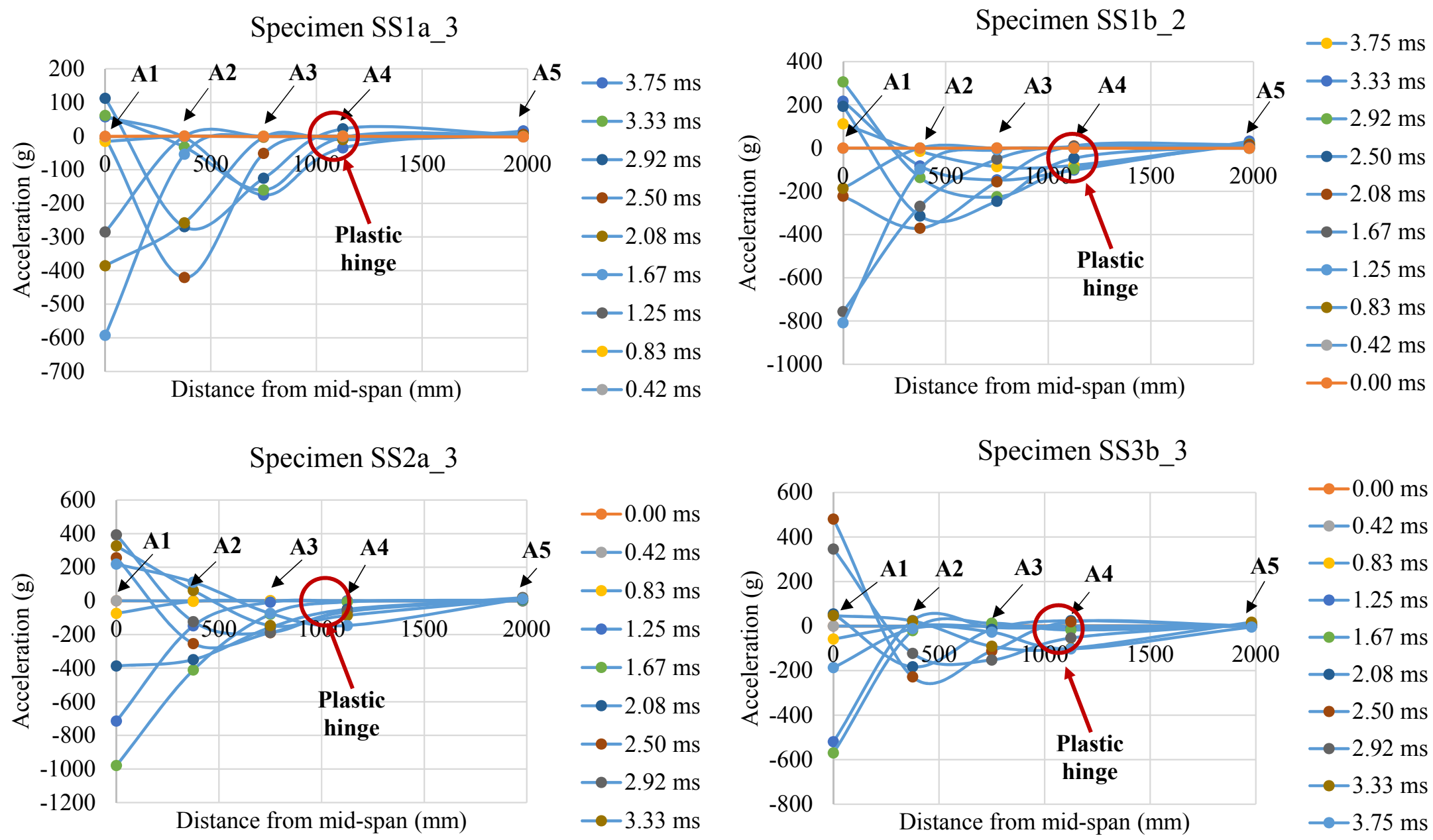


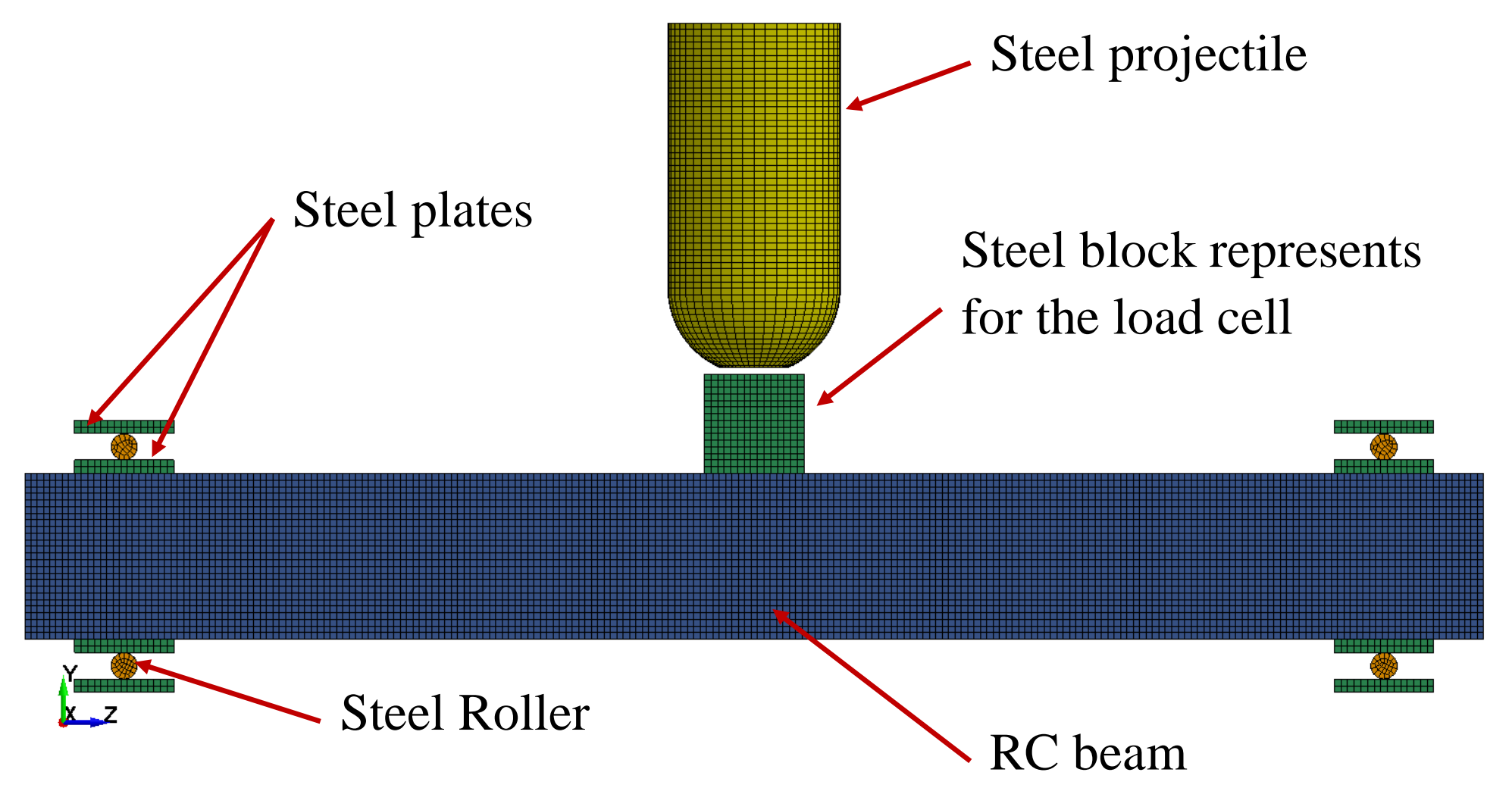




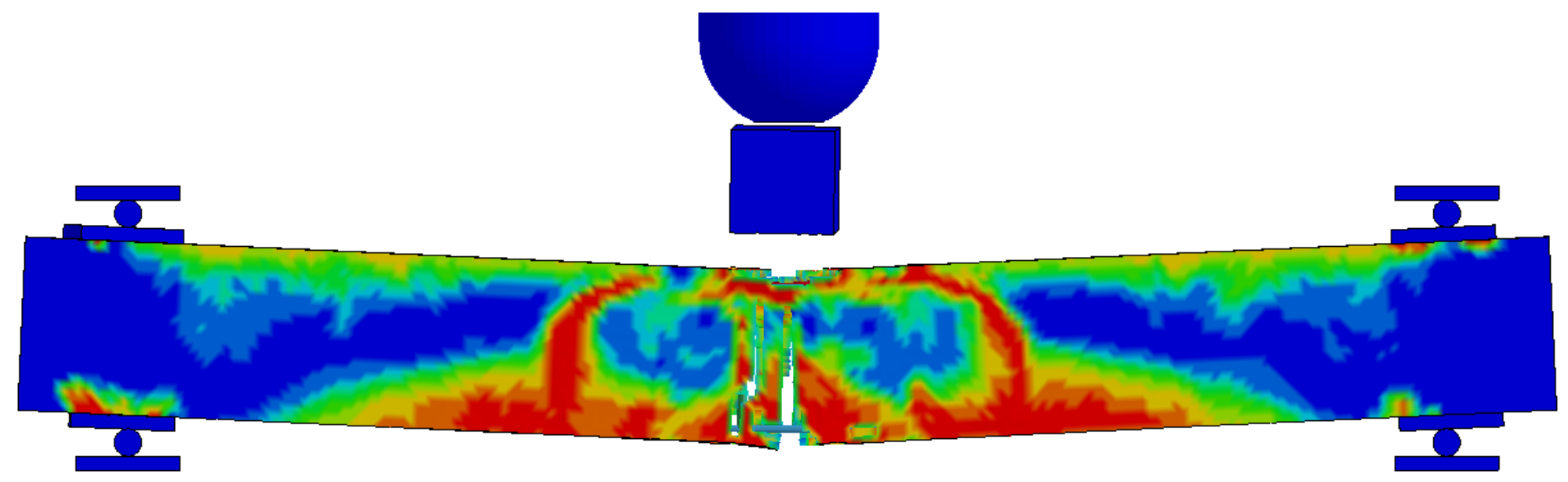

Fringe Levels

$2.000 \mathrm{e}+00$

$1.800 \mathrm{e}+00$

$1.600 \mathrm{e}+00$

$1.400 \mathrm{e}+00$

$1.200 \mathrm{e}+00$

$1.000 \mathrm{e}+00$

$8.000 \mathrm{e}-01$

$6.000 \mathrm{e}-01$

$4.000 \mathrm{e}-01$

2.000e-01

$0.000 \mathrm{e}+00$

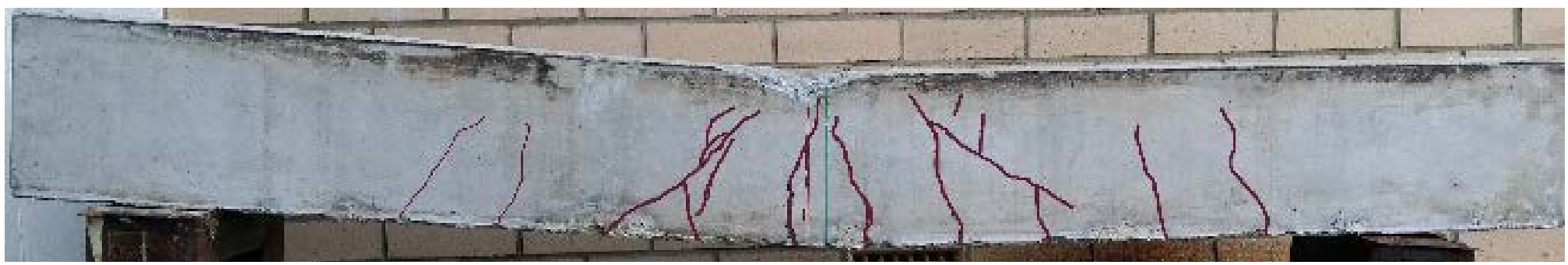

(b) Failure of the RC beam after testing 
Fig. 9

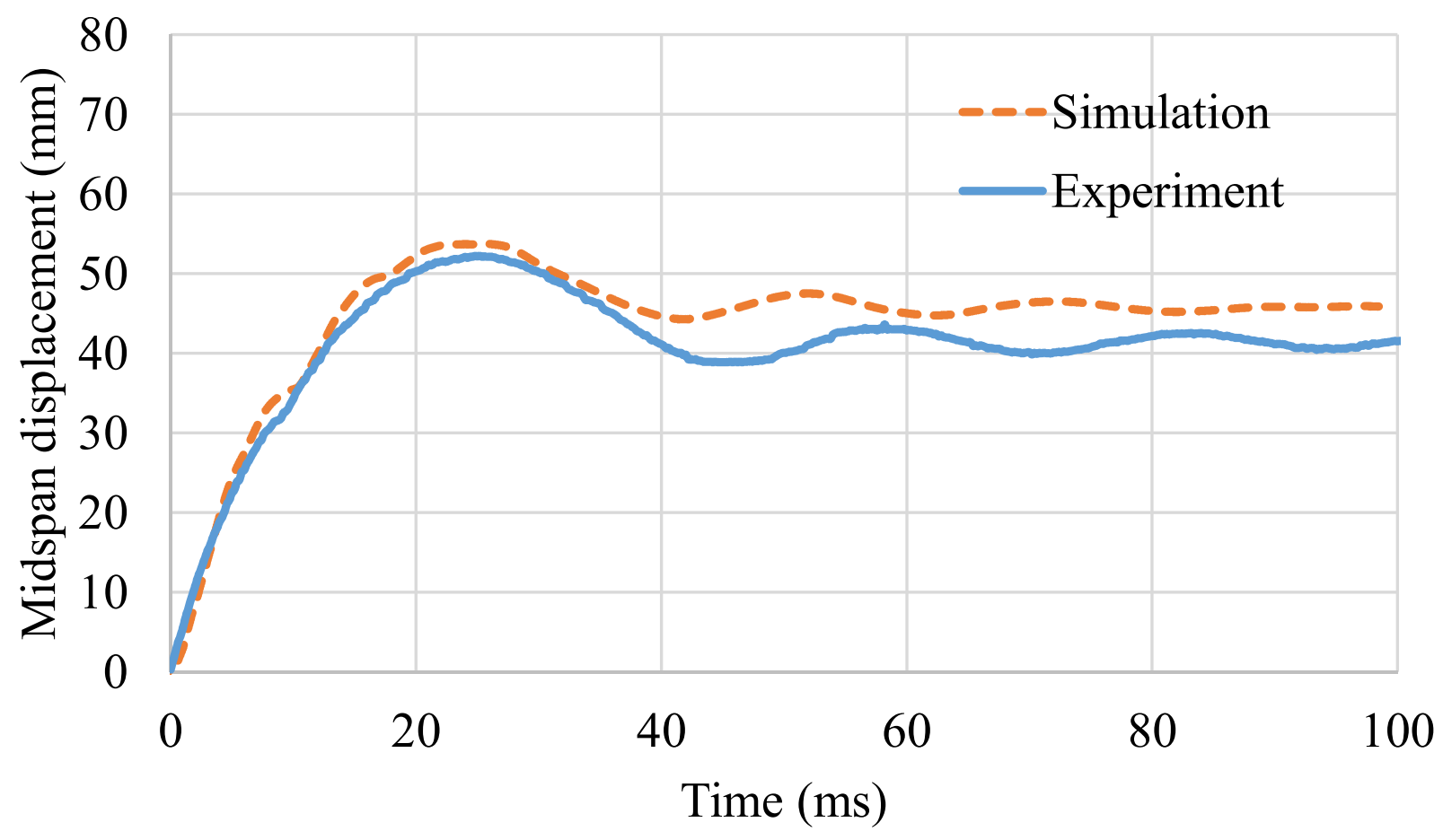


Fig. 10

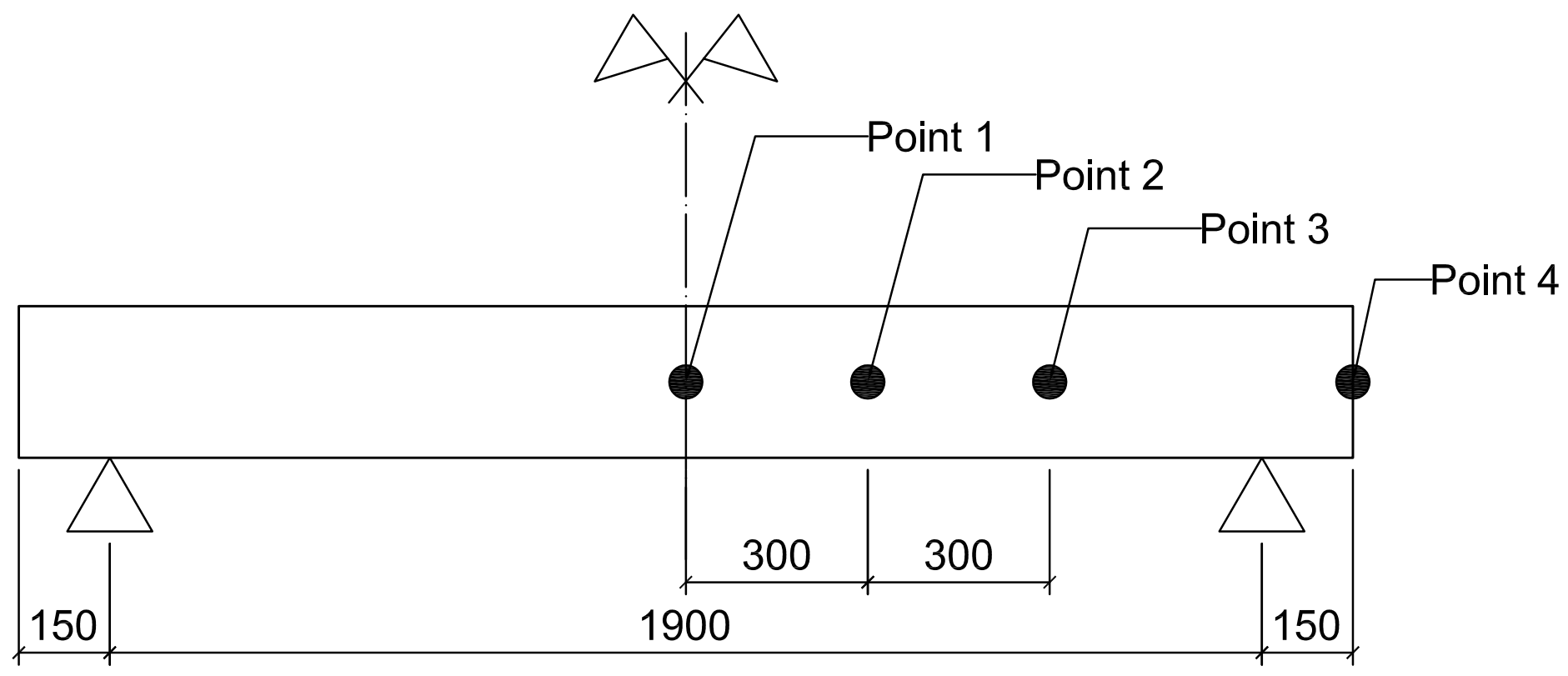


Fig. 11

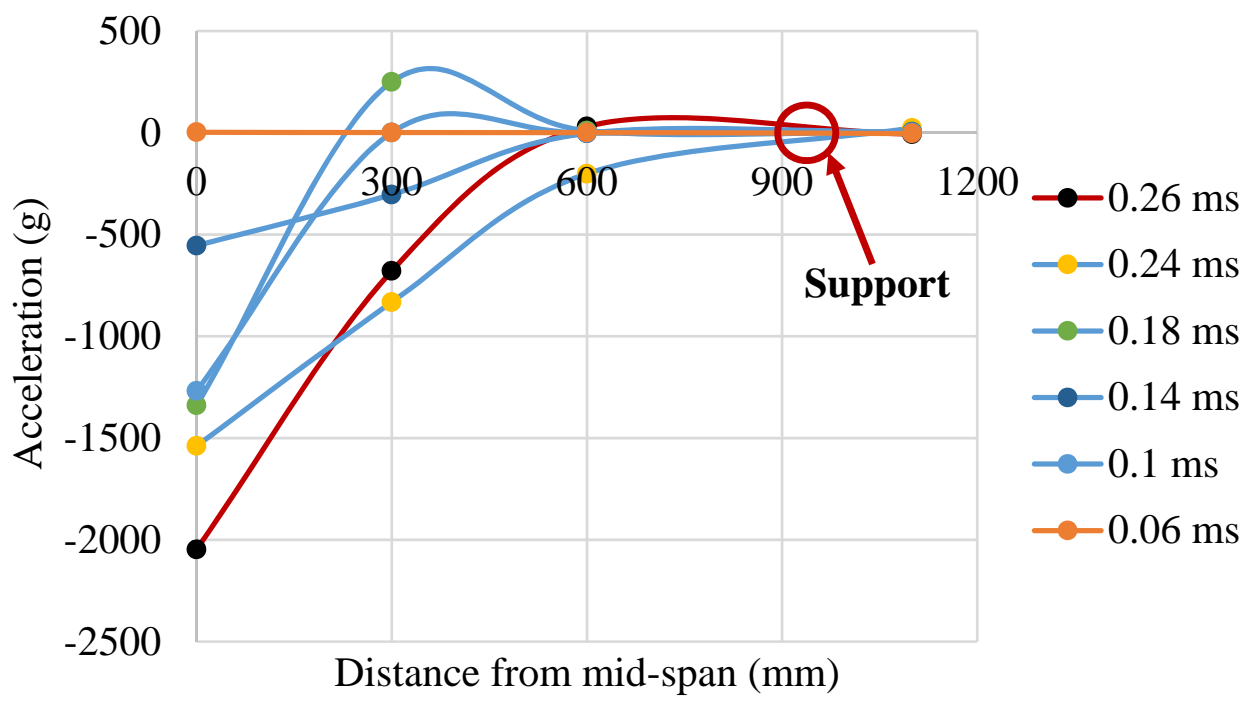


Fig. 12

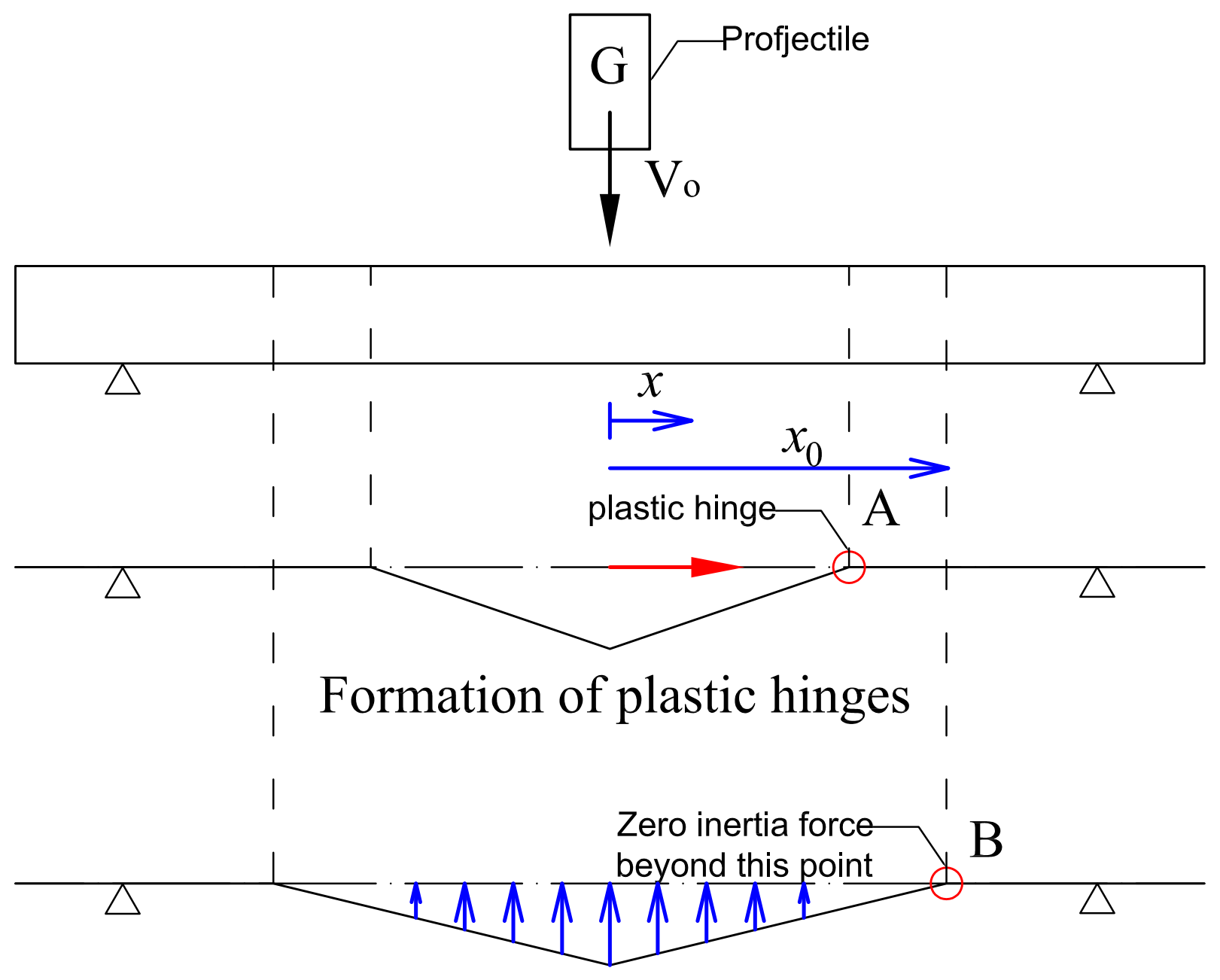

Inertia force distribution 
Fig. 13

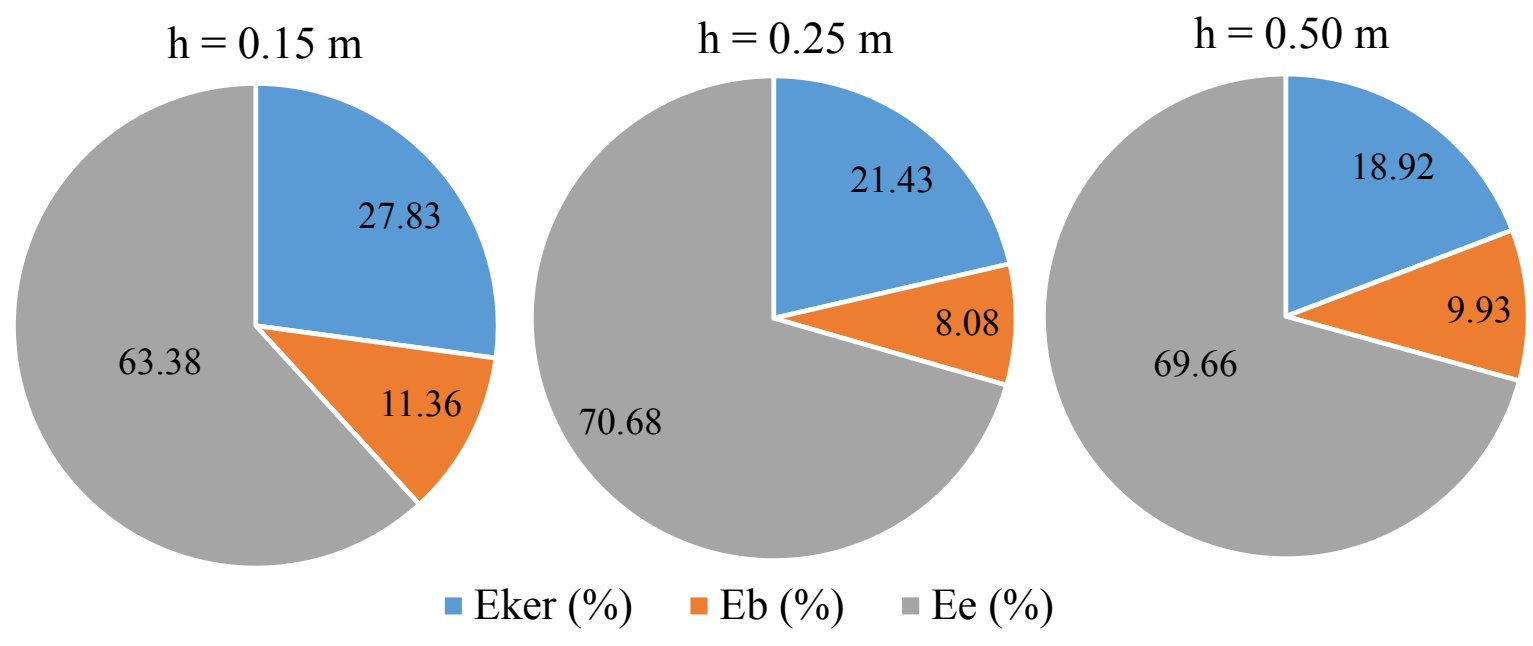


Fig. 14

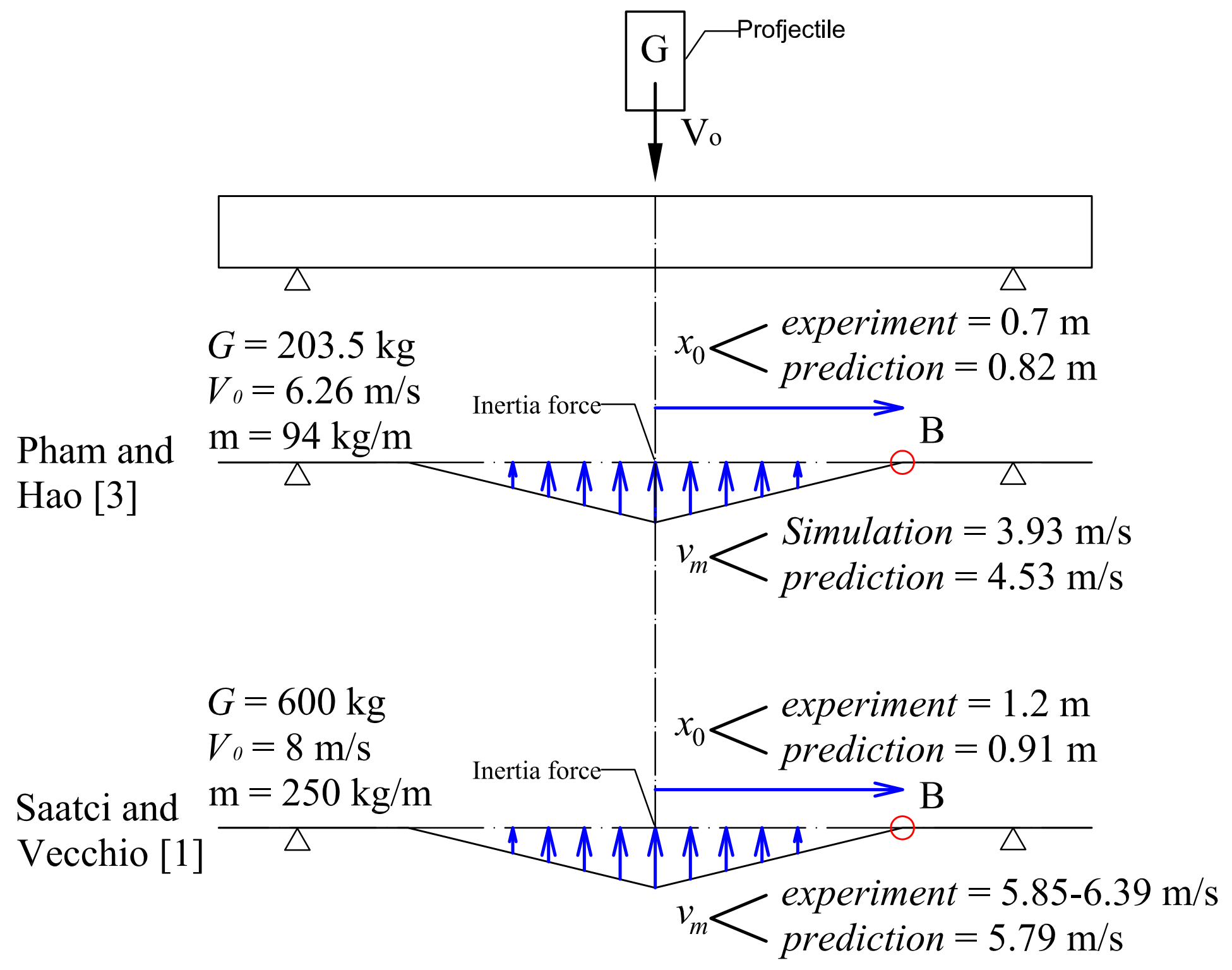


Fig. 15

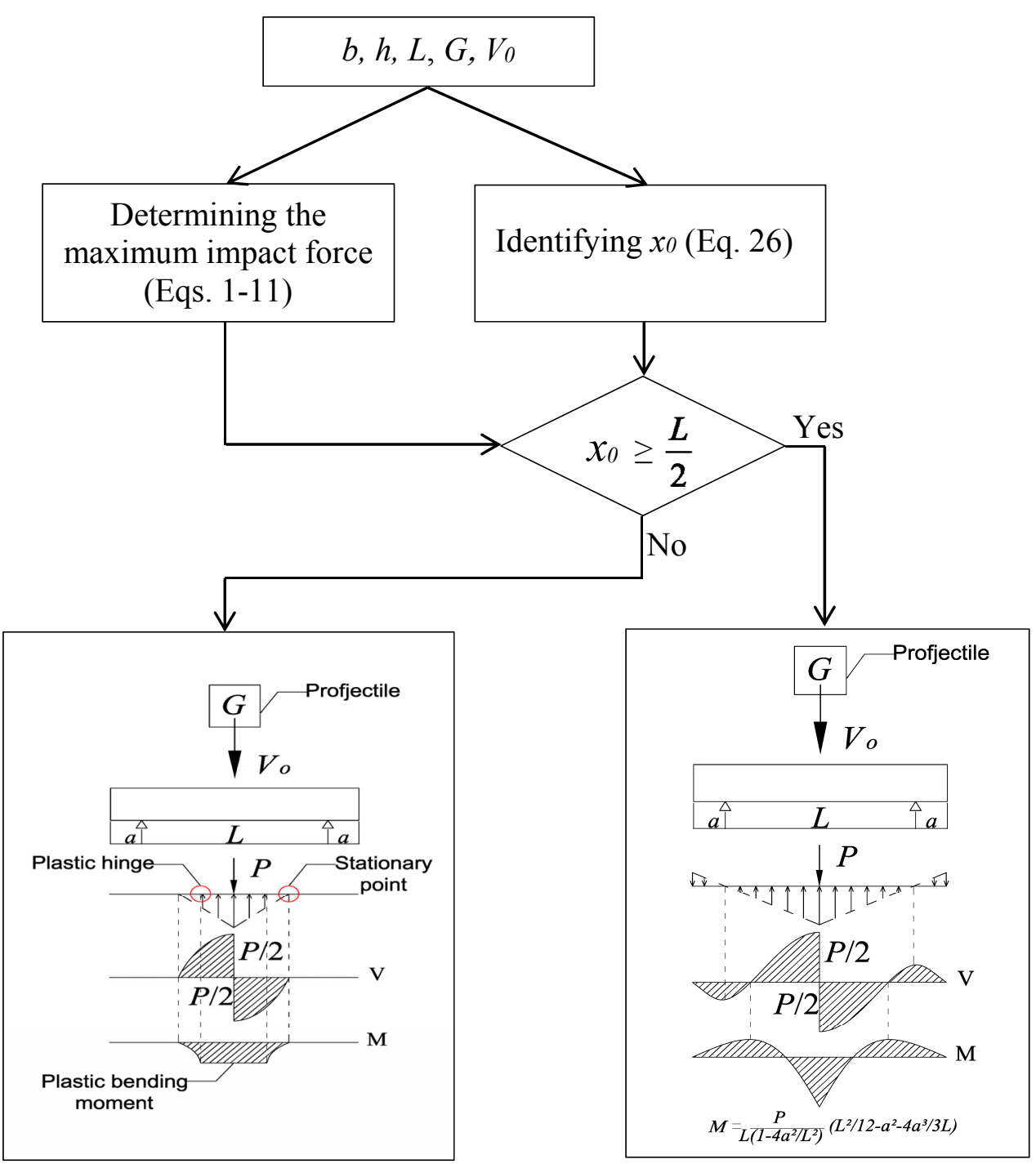

